\title{
Gab es eine „,Kölner Schule“ der bundesrepublikanischen Soziologie? Zu René Königs Professionalisierung der Soziologie
}

\author{
Stephan Moebius • Martin Griesbacher
}

Online publiziert: 3. Dezember 2019

(C) Der/die Autor(en) 2019

Zusammenfassung Nach dem 2. Weltkrieg etablierten sich mehrere Zentren der bundesrepublikanischen Soziologie. Neben den Frankfurtern Theodor W. Adorno und Max Horkheimer und dem Münsteraner Helmut Schelsky war es René König, der in Köln die Soziologie neu ausrichtete und wesentlichen Anteil an ihrer Institutionalisierung und Professionalisierung hatte. Oft wurde im Zusammenhang dieser „Ausgangskonstellation“ (Lepsius) von „drei Soziologien“ (Dahrendorf) gesprochen, wobei auch explizit von einer „Kölner Schule“ die Rede war. Inwiefern kann jedoch von einer bundesrepublikanischen „Kölner Schule“ tatsächlich ausgegangen werden? Der folgende Beitrag möchte die verbreitete Bezeichnung „,Kölner Schule" sowie deren Merkmale kritisch hinterfragen und diskutieren. Nach einer Auseinandersetzung mit soziologiegeschichtlichen Konzepten zur Erfassung wissenschaftlicher Kollektive wird anhand des soziologischen Schulenbegriffs geprüft, ob die Kölner Soziologie von 1945 bis Mitte der 1970er-Jahre zentrale Kriterien einer Schule erfüllt hat. Dabei wird erstens René König als „,charismatischer Stifter“ der kognitiven Leitideen (sowohl theoretischer als auch methodischer Art) der Kölner Soziologie positioniert. Zweitens werden die Institutionalisierungs- und Professionalisierungsprozesse in Köln und deren Öffentlichkeitswirkung anhand einer knappen Geschichte des Instituts, der Kölner Zeitschrift für Soziologie und Sozialpsychologie (KZfSS) sowie einiger weiterer „Flaggschiffpublikationen“ wie das Fischer-Lexikon und das Handbuch der empirischen Sozialforschung skizziert. Drittens wird auf die Bindung weiterer soziologischer Akteure (Schüler) durch die Lehre René Königs eingegangen. Wie bei dem Lexikon, den Handbüchern oder der KZfSS (und insbe-

\footnotetext{
S. Moebius $(\bowtie) \cdot$ M. Griesbacher Institut für Soziologie, Karl-Franzens-Universität Graz Universitätsstraße 15/G4, 8010 Graz, Österreich

E-Mail: stephan.moebius@uni-graz.at

M. Griesbacher

E-Mail: m.griesbacher@uni-graz.at
} 
sondere ihrer Sonderhefte) zeigt sich eine breite Palette an Themen und Schülern, die der üblichen Reduzierung des Kerns der „Kölner Schule“ auf empirische Sozialforschung nicht gerecht wird. Der Beitrag zeigt stattdessen, dass der schulenbildende Kern der Kölner Soziologie vielmehr in der von König ins Leben gerufenen, dezidiert empirisch orientierten, problemzentrierten Ausdifferenzierung, Spezialisierung und Professionalisierung der bundesrepublikanischen Soziologie gesehen werden muss. Insofern umfasste die von König initiierte „Kölner Schule“ durchaus die Kriterien eines soziologiegeschichtlichen Schulenbegriffs, was aber aus heutiger Sicht aufgrund der schlussendlichen Popularisierung und Veralltäglichung ihrer Leitideen im soziologischen Betrieb aus dem Blick geriet.

Schlüsselwörter „Kölner Schule“ · René König · Kölner Zeitschrift für Soziologie und Sozialpsychologie · Geschichte der Soziologie in Deutschland nach 1945 . Wissenschaftliche Kollektive

\section{Was There a "Cologne School” of West German Sociology? On René König's Professionalization of Sociology}

Abstract After the Second World War, several centres of West German sociology were established. Alongside Theodor W. Adorno and Max Horkheimer from Frankfurt and Helmut Schelsky from Münster, it was René König who realigned sociology in Cologne and played a major role in its institutionalization and professionalization. In the context of this "initial constellation" (Lepsius), the "three sociologies" (Dahrendorf) were discussed, including explicit references to a "Cologne school" ("Kölner Schule"). To what extent, however, can a "Cologne school" in the Federal Republic of Germany be actually assumed? The following article sets out to critically scrutinize and discuss the widespread designation "Cologne School", as well as its characteristics. After an examination of sociological-historical concepts of scientific collectives, the sociological concept of schools is used to examine whether Cologne's sociology from 1945 to the mid-1970s fulfilled the key criteria of a school. First, René König is positioned as a "charismatic founder" of the cognitive guiding principles (both theoretical and methodological) of Cologne sociology. Second, the institutionalization and professionalization processes in Cologne and their public impact are outlined based on a brief history of the Institute, the Cologne Journal of Sociology and Social Psychology, and several other "flagship publications", such as the Fischer Lexicon and the Handbook of Empirical Social Research. Third, the involvement of other sociological players (scholars) is dealt with through René König's teaching. As with the lexicon, the handbooks or the Cologne Journal of Sociology and Social Psychology (particularly its special issues), there is a wide range of topics and scholars that do not do justice to the usual reduction of the core of the "Cologne School" to empirical social research. Instead, the article demonstrates that the school-forming core of Cologne sociology should rather be seen in the decisively empirically oriented, problem-centred differentiation, specialization and professionalization of West German sociology brought about by König. Although the "Cologne School" that was initiated by König certainly encompassed the criteria of the sociological-historical concept of a school, it has, however, been overlooked 
because of the eventual popularization and routinization of its guiding principles within the sociological establishment.

Keywords Cologne School · René König · Cologne Journal of Sociology and Social Psychology $\cdot$ History of Sociology in Germany after $1945 \cdot$ Scientific collectives

\section{Einleitung: Die „Kölner Schule“ und René König}

Gemeinhin wird in der Soziologiegeschichtsschreibung der frühen bundesrepublikanischen Soziologie von 3 Schulen ausgegangen: der „Kölner Schule“, der „Frankfurter Schule“ und dem Kreis um Helmut Schelsky (vgl. Dahrendorf 1960; Moebius 2015a), zuweilen wird noch die Marburger Schule genannt (vgl. Sahner 1982; Peter 2014). ${ }^{2}$ Während zahlreiche Überblicksartikel oder Bücher von der „Frankfurter Schule“ handeln (vgl. Wiggershaus 1988; Kraushaar 1998; Albrecht et al. 1999), hat man über die „Kölner Schule“ als Schulzusammenhang bislang kaum etwas gelesen. Vielleicht hat es ja eine „Kölner Schule“ der Soziologie gar nicht gegeben? Zumindest die Zeitgenossen sind sich darin nicht einig: René König (1987, S. 323), der gemeinhin als der führende Repräsentant und Begründer einer „Kölner Schule“ gilt, spricht im Zusammenhang der Situation der remigrierten Soziologen explizit von einer „Kölner Schule“. Lepsius (2017, S. 81) ebenfalls. Günter Lüschen (1995, S. 21), Habilitand bei König und ehemaliger Präsident der René-KönigGesellschaft, geht in einem soziologiehistorischen Rückblick nicht nur davon aus, dass die „Kölner Schule“ die deutsche Soziologie wieder in die internationale Soziolog*innengemeinschaft zurückgeführt habe, sondern auch, dass Köln ,unter den Schulen in den 1950er- und 1960er-Jahren ... die am deutlichsten erkennbare Schule“ gewesen sei. Peter Atteslander (1998, S. 138), ein früher Schüler Königs aus der Zeit des Zürcher Exils, bestreitet hingegen, dass es eine solche Schule je gegeben habe. Königs Wirkung sei zu vielfältig gewesen, als dass man sie im Sinne einer Schule einhegen könne (Atteslander 1996, S. 178). Und Erwin K. Scheuch (1998, S. 241), ebenfalls zentraler Repräsentant einer Soziologie aus Köln und ehemaliger Assistent Königs, meint, eine richtige Schule sei das nicht gewesen, eher ein „Kreis mit einem übereinstimmenden Vorverständnis von Gesellschaft und den Methoden, mit denen über diese Informationen beschafft werden können. Intern gab es erhebliche Akzentsetzungen für Mikro- oder Makrosoziologie, für die Art der Faktensammlung,

\footnotetext{
${ }^{1}$ Es ist schwierig auszumachen, seit wann genau in der Soziologie von einer „Kölner Schule“ gesprochen wird. Frühe dokumentierte Hinweise finden wir bei Lepsius (2017) und beispielsweise bei Gert Schmidt, der im Kontext der Geschichte der Industriesoziologie in der BRD ganz selbstverständlich von einer „,Kölner Schule - unter Führung René Königs“ ausgeht (1980, S. 267f.) - wir können entsprechend davon ausgehen, dass informell bereits früher davon die Rede war.

2 Es werden in Überblicksartikeln oder -bänden in jüngerer Zeit auch weniger institutionalisierte, also mit bestimmten Instituten oder Zeitschriften assoziierte Denkschulen wie die Philosophische Anthropologie, poststrukturalistische Milieus oder die Erklärende Soziologie etwa in der Soziologiegeschichte soziologischer Schulen mitaufgenommen (vgl. Moebius 2017a; Fischer und Moebius 2019).
} 
der Orientierung eher an Durkheim oder an Weber oder an Parsons. " ${ }^{3}$ Und Johannes Weiß (1992) schließlich fragt gar: „Gehört René König zur ,Kölner Schule“?“ Kann man wirklich von einer „Kölner Schule“ sprechen, wenn selbst ihr zugerechnete „Schüler“ und unmittelbar Beteiligte einen solchen Denk-, Forschungs-, Lehr- und Interaktionszusammenhang bestreiten?

Im Folgenden sollen zunächst in einer Auseinandersetzung mit soziologiegeschichtlichen Konzepten zur Erfassung wissenschaftlicher Kollektive zentrale Kriterien des Schulenbegriffs bestimmt werden (Abschn. „Schule“ als soziologiegeschichtliche und erkenntnisleitende Kategorie). Im Anschluss daran wird die Kölner Soziologie von 1945 bis Mitte der 1970er-Jahre in 3 Schritten hinsichtlich dieser Kriterien geprüft (Abschn. Gab es eine „Kölner Schule“?). Unter welchen Voraussetzungen kann man eine „Kölner Schule“ der bundesrepublikanischen Soziologie ${ }^{4}$ im Nachhinein konstruieren oder feststellen? Lässt sich ein schulentypischer Kern ausmachen, etwa anhand der Publikationen, der Kölner Zeitschrift für Soziologie und Sozialpsychologie (KZfSS) und der „Schülerschaft“ um René König, der es rechtfertigt, von der „Kölner Schule“ zu sprechen? Worin bestünde dann das Schulentypische? Im Fazit (Abschn. Fazit) geben wir ein Resümee unserer These von der „Kölner Schule“.

\section{2 ,Schule“ als soziologiegeschichtliche und erkenntnisleitende Kategorie}

In der Soziologiegeschichte und Wissenschaftssoziologie werden mittlerweile eine Reihe soziologischer Konzeptualisierungen kollektiver Wissensgenerierung und -distribution unterschieden (vgl. Dayé 2016, 2017), man spricht beispielsweise von Denkkollektiv, der wissenschaftlichen Gemeinschaft (scientific community), dem unsichtbaren Kollegium (the invisible college), dem kollaborativen Zirkel, dem akademischen Stamm, der epistemic community, der Wissenskultur oder eben der wissenschaftlichen Schule.

Bezogen auf die Anfänge der bundesrepublikanischen Soziologie kann man durchaus unterschiedliche „Denkkollektive“ (Ludwik Fleck) ausmachen, die trotz anfänglich ähnlicher Themenstellungen und -interessen (Familie, Industriegesellschaft, Massenkultur, empirische Sozialforschung) eigene Denkstile und Herangehensweisen an die Themen entwickelt haben, die jedoch größtenteils den unterschiedlichen intellektuellen Prägungen (Philosophische Anthropologie etwa bei Schelsky, Durkheim-Schule und Kulturanthropologie bei König, Marxismus und Psychoanalyse bei Horkheimer/Adorno, Marxismus bei Abendroth) geschuldet waren (vgl. Moebius 2015a, S. 9-33, 2017a). Allein der Blick auf das Konzept

\footnotetext{
3 Der Begriff des „Kreises“ scheint hier sicherlich unangebracht, da er Assoziationen an den George-Kreis wachruft, eine Sozialform, die König seit Ende der 1930er-Jahre vehement abgelehnt hat. Diesen Hinweis verdanken wir Oliver König, dem wir hier an dieser Stelle ganz herzlich für seine hilfreiche Unterstützung bei unseren Forschungen zu René König und der Edition der Zürcher Vorlesungen danken möchten.

4 Im Mittelpunkt steht dabei die Kölner Soziologie nach 1945 um René König. Die Frage, ob die Kölner Soziologie zwischen 1919 und den 1930er-Jahren eine eigene „Kölner Schule“ ausmacht, soll hier nicht behandelt werden.
} 
der Denkkollektive reicht aber zur Bestimmung der „Kölner Soziologie“ unseres Erachtens nicht aus, da dieses Konzept beispielsweise einige typische Kennzeichen wissenschaftlicher Zusammenhänge vermissen lässt, die man hingegen beim Konzept der „wissenschaftlichen Schule“ und beim Blick auf eine „Kölner Schule“ wiederfindet, so etwa die ,generationsübergreifende Komponente“ (vgl. Klausnitzer 2014, S. 14f.; J.-H. König 2014, S. 21), die Institutionalisierung qua Zeitschrift sowie die lokale Verankerung. Der Fokus auf Denkkollektiv und Denkstil vernachlässigt zudem aufgrund einer Überbetonung der kognitiven Aspekte die sozialstrukturellen Merkmale sowie spezifische Arten der Wissenschaftskommunikation und -distribution - ähnlich dem Kuhn'schen Paradigmenbegriff, der vornehmlich auf die ,vergleichbare Art \& Weise, die Welt zu sehen und die Wissenschaft in ihr auszuüben“ (Kuhn 1973, S. 21) abzielt.

Das Konzept der scientific community mag weiterhelfen, da es mit dem Verweis auf „Gemeinschaft“" neben kognitiven Übereinstimmungen auch auf die sozialen und affektiven, rituellen und „quasi-familialen“ (Stichweh 1999, S. 26) Elemente verweist. Ebenso kommen normative Aspekte wie Belohnung, Bestrafung, (positive oder negative) Sanktion und Kontrolle in den Blick. Der Aspekt der Kontrolle muss dabei nicht nur auf den Bereich der unmittelbaren sozialen Interaktionen innerhalb des Kollektivs beschränkt sein, sondern kann gleichermaßen die Kontrolle über die Weitergabe, Fortführung und Ausbildung des Paradigmas/Denkstils meinen. Was jedoch bei diesem Konzept zu schnell aus dem Blick gerät, ist die (integrative) Dimension von Konflikten sowie explizite Lehrer-Schüler-Beziehungen. Dass solche Hierarchiebeziehungen jedoch ,durchgängig als Strukturprinzip“ wissenschaftlicher Schulen fungieren, hat Rudolf Stichweh (1999) hervorgehoben. Ihm zufolge bedeutet jedoch eine Hierarchie in der Lehrer/Schüler- bzw. „Patron/Klient“-Beziehung nicht, ,daß die intellektuellen Beziehungen von Lehrern und Schülern einseitig sind, daß Reziprozität abwesend ist. Das intellektuelle System des Lehrers, das wissenschaftliche Projekt, dem er sich verpflichtet hat, ist ja nicht in jedem einzelnen Fall als bereits konsolidiert anzusehen, sodaß es nur noch der Fortschreibung ... bedürfte. Weil dies aber so ist, bilden vielfach die Schüler für den Lehrer ein protektives Sozialsystem, das eine vorläufig prekäre wissenschaftliche Innovation vor ihrer sofortigen Zerstörung durch Kritik schützt. ... Die Reziprozität der Leistungen erzeugt dann eine Reziprozität der Verpflichtungen, eine Verpflichtung des Lehrers auf die Karrieren seiner Schüler.“ (Stichweh 1999, S. 25 f.).

Eng verwandt mit dem Konzept der scientific community ist das Konzept des akademischen Stamms (Becher 1989; Becher und Trowler 2001; vgl. Dayé 2017, S. 73 ff.). Im Unterschied zu der Berücksichtigung der normativen Strukturen im Konzept der scientific community hebt es auf die situativen Aushandlungs- und alltäglichen Interpretationsprozesse dieser normativen Strukturen ab und entwickelt ausgehend davon eine praxistheoretische Perspektive auf den „Stamm“ und dessen Wissensproduktion. Was jedoch bei dem Blick auf die community, den Stamm oder das „unsichtbare Kolleg“ (vgl. Crane 1972; de Solla Price 1974) kaum in den Blick kommt, sind einerseits die kognitiven Dimensionen (vgl. Peter 2015, S. $119 \mathrm{ff}$.), also die Frage der Ideenproduktion und -distribution jenseits rein sozialer Faktoren (auf welche Ideen beruft man sich, was sind paradigmatische Einflüsse und Ideenkontexte etc.?). Andererseits finden in diesen Klassifizierungskonzepten auch etwaige Insti- 
tutionalisierungsprozesse, wie sie etwa Department- oder Institutsgründungen oder die Herausgabe von Zeitschriften darstellen, keine ausreichende Berücksichtigung. ${ }^{5}$ Auch das Konzept der ,kollaborativen Zirkel“" von Michael P. Farrell (2001) beinhaltet solche Institutionalisierungsprozesse, wie man sie bei der Kölner Soziologie ja beobachten kann, nicht. Bei Farrells Konzept stehen die Entstehungsprozesse wissenschaftlicher Gruppierungen aus Freundschafts- oder Bekanntschaftsbeziehungen im Vordergrund (vgl. Dayé 2017, S. 72f.). Das mag für andere wissenschaftliche oder künstlerische Gruppierungen wie den Surrealismus oder auch das Collège de Sociologie (vgl. Moebius 2006) ein brauchbares heuristisches Konzept sein, da ein wesentliches Kriterium eines kollaborativen Zirkels nach Farrell die Rebellion gegen bestehende Autoritäten ist. Für die Analyse der Kölner Nachkriegssoziologie scheint es aber nur bedingt brauchbar, da sich diese nicht aus einem Zirkel Gleichgesinnter gebildet hat, der gegen bestehende Autoritäten (in Bourdieu'scher Begrifflichkeit „Orthodoxe“) anzukämpfen versuchte. Ausgangspunkt der Gruppenbildung war vielmehr das leidenschaftliche Engagement René Königs für eine an der USamerikanischen empirischen Sozialforschung und der Soziologie Durkheims orientierte Neuausrichtung, Institutionalisierung und Professionalisierung der Soziologie nach 1945.

Wir finden also bei den diskutierten zentralen soziologiegeschichtlichen Konzepten zur Analyse wissenschaftlicher Kollektive Vorannahmen vor, die die Behandlung von entweder kognitiven, kommunikativen oder organisatorischen Aspekten größeres analytisches Gewicht zuteilwerden lassen oder gar wesentliche Merkmale wissenschaftlicher Zusammenarbeit auslassen. Tatsächlich erlaubt der Schulenbegriff unseres Erachtens hingegen eine ausgewogene Behandlung kognitiver, sozialer und institutioneller Aspekte. Im Anschluss an Lothar Peter definieren wir ,als Schule die institutionelle Formierung einer soziologisch sowohl zeitlich als auch räumlich einflußreichen theoretischen und/oder empirischen Konzeption sowie die damit einhergehende formelle oder informelle Einbindung von soziologischen Akteuren in einen institutionalisierten Zusammenhang von Forschung, Lehre, Publikation und öffentlicher Präsenz." (Peter 2001, S. 43; vgl. auch Peter 2014, S. 9 ff.). ${ }^{6}$ Zentral sei ein ,kognitives Zentrum eines Paradigmas, einer Leittheorie oder einer regulativen moralischen Idee“ (Peter 2001, S. 43), die sich in vielen Fällen ,außergewöhnlichen Leistungen von (manchmal charismatischen) Einzelpersönlichkeiten“ (Peter 2014, S. 9) verdanken. „Der spezifische Charakter einer Schule kann sich aber erst dann herausbilden, wenn die Tätigkeit dieser Einzelpersönlichkeiten dazu führt, dass sich weitere Akteure mit ihnen identifizieren und in einen nicht vorübergehenden Interaktionszusammenhang treten" sowie das Paradigma oder die Leitidee, mit der sie identifiziert wird, ,auch aktiv in der Öffentlichkeit“" vertreten (Peter 2014, S. 10).

\footnotetext{
${ }^{5}$ Für eine genaue Analyse, ob die Kölner Nachkriegssoziologie auch ein invisible college sei, müsste man Zitations-, Netzwerk- oder andere bibliometrische Analysen durchführen, um hiermit die Kommunikations- sowie Machtbeziehungen innerhalb der wissenschaftlichen Gemeinschaft der Schüler detaillierter aufzuschlüsseln. Dabei wäre auch nicht nur an das wechselseitige Zitieren oder den gegenseitigen Austausch wissenschaftlicher Arbeiten (wie zum Beispiel Manuskriptfassungen, Vorabversionen) gedacht, sondern auch an Briefwechsel und andere informelle Kommunikationskanäle.

${ }^{6}$ Dabei greift Peter auf die Überlegungen von Jerzy Szacki (1981) und Edward A. Tiryakian (1981) zurück.
} 
Tiryakian (1981) betont darüber hinaus in seiner Definition von „Schule“, dass die Bildung einer solchen oft vor dem Hintergrund als anomisch wahrgenommener Prozesse stattfindet, die nach neuen Orientierungsmustern und affektiven Bindungen an neue Lehrsätze verlangen. Ferner hebt er die Missionsbereitschaft hervor: „Die Schule mag das stillschweigende Gefühl haben, der Profession die Rettung zu bringen, mit anderen Worten, sie aus einem Zustand der Stagnation und/oder Niedergang zu erlösen; die Schule versucht, der Profession ,neue Kleider zu verpassen“, sie zu modernisieren, zu erneuern, ihr einen neuen Anfang zu ermöglichen." (Tiryakian 1981, S. 41). Der Missionswille kann auch über die Disziplin hinaus die Gesellschaft als solche betreffen, wie Tiryakian an seinem Beispiel der Durkheim-Schule verdeutlicht. Zuweilen kann dann eine Schule eine solche Eigendynamik entfalten (vgl. Tiryakian 1981, S. 43), dass es zum symbolischen ,Vatermord“ kommt und ein Teil der Schüler sich gegen den oder die Gründer wendet - politisch, methodisch, theoretisch, lebensweltlich. Bei zunehmender Institutionalisierung und Sichtbarkeit der Schule kommt es nach Tiryakian (1981, S. 42) darüber hinaus zu einer Popularisierung und Veralltäglichung ihrer Grundideen.

Zusammenfassend kann hervorgehoben werden, dass der Schulenbegriff als erkenntnisleitende soziologiegeschichtliche Kategorie unsere Aufmerksamkeit auf ein kognitives Zentrum mit theoretischen und empirischen Leitideen, der sozialen und kognitiven Bindung weiterer soziologischer Akteure (Schülerinnen und Schüler) und einen institutionalisierten Zusammenhang von Forschung, Lehre und Publikation lenkt. Entsprechend wenden wir bei der Frage nach der „Kölner Schule“ unsere Aufmerksamkeit im nachfolgenden Kapitel diesen Aspekten systematisch zu.

\section{Gab es eine „Kölner Schule“?}

Für die Beantwortung der Frage, ob es eine „Kölner Schule“ gab, sind 2 Dinge relevant: Zum einen sollte man durchaus einen ,,epistemologischen Bruch“ (Bachelard; vgl. Bourdieu et al. 1991, S. 15 ff.) mit den zeitgenössischen Aussagen wagen und ihnen nicht ungeprüft folgen; ferner scheinen Schulenzuschreibungen in der Regel immer nachträgliche Typisierungen zu sein (vgl. Sahner 1982; Mikulinskij et al. 1977a, b; Stichweh 1999), die zuweilen die Funktion der nachträglichen Legitimierung eines bestimmten Denkstils erfüllen (vgl. J.-H. König 2014, S. 22). Das verweist zum anderen auf die Bedeutung der konzeptionellen Auseinandersetzung mit dem Begriff der ,Schule“.

Auf den ersten Blick finden wir für eine „Schule“ gemäß der oben genannten Kriterien bedeutende Anzeichen, charismatische Hauptpersonen oder Gründer: König als geschickter, fördernder und aktiv in der Öffentlichkeit agierender Initiator; später daneben der ebenfalls öffentlich engagierte Erwin Scheuch als zweite Hauptperson, der insbesondere die quantitativ-empirische Ausrichtung der Kölner Soziologie aufund ausbaut. Er hat die von Tiryakian (1981, S. 44) beschriebene zentrale Rolle des „Popularisierers“ der empirischen Sozialforschung; es gibt eine auf die Schule bezogene Lehre, eine Zeitschrift und eine Schülerschaft mit diffundierender Wirkung und einen sowohl auf die Gesellschaft als auch auf die Disziplin ausgerichteten Missionswillen (vgl. Hummell 1998, S. 311) (entgegen transzendentaler Soziologie 
Schelskys und Geschichtsphilosophie der Frankfurter Schule eine wirklichkeitsbezogene Soziologie zu etablieren). Hinzu kommen die anomischen gesellschaftlichen Verhältnisse der Nachkriegszeit (vgl. Reichardt und Zierenberg 2009), die nach Orientierung und Aufklärung verlangten. Aber bei genauerem Hinsehen mag man vielleicht Zweifel bekommen, ob wirklich von einer Schule gesprochen werden kann. Wir werden diesen Beitrag dazu nutzen, die einzelnen konzeptionellen Eckpunkte des Schulenbegriffs (Lehrer/Gründer, Leitideen, Schüler, Lehre, Forschung, Publikationen und Zeitschrift) in den nachfolgenden 3 Abschnitten in knapper Form etwas näher zu betrachten. Wir können die Eckpunkte dabei nicht entlang einer historisch linearen Erzählung erfassen, sondern müssen bei der Betrachtung gewissermaßen unterschiedliche Aspekte der historischen Entwicklung jeweils hervorheben.

\subsection{Charismatischer Stifter der Leitideen: René König}

Die entscheidende Wende der Kölner Nachkriegssoziologie setzt 1949 mit dem Ruf von René König auf den Lehrstuhl für Soziologie ein. ${ }^{7}$ Scheuch (2001, S. 144) spricht im Rückblick von einer regelrechten ,Aufbruchsstimmung“ der Kölner Soziologie der 1950er-Jahre, die durch König eingeläutet wurde. 1949 befindet sich König noch in Zürich, wohin er 1937 ins Exil getrieben wurde. In der Züricher Zeit erweitert König, der mit einer literatursoziologischen Arbeit Anfang der 1930er-Jahre promoviert hatte (vgl. Moebius 2016), seinen breiten Horizont an Interessen und Wissen, habilitiert dort mit einer Schrift über Durkheim (vgl. Albrecht 2002) und publiziert zahlreich - zu erwähnen sind etwa Machiavelli. Zur Krisenanalyse einer Zeitenwende (1941), Sizilien (1943), Materialien zur Soziologie der Familie (1946) und die programmatische Schrift Soziologie heute (1949), eine kritische, ,soziologisch-gegenwartswissenschaftliche“ Auseinandersetzung mit den ,endgeschichtlichen Visionen“ und der These des Verschwindens der Mittelklasse von Marx (König 1949, S. 37). König verfasst über 360 Artikel über die Soziologie für das Schweizer Lexikon. Jahre später werden diese den Grundstock für Königs berühmten Kanonisierungsversuch des Fachs durch das 1958 erschienene Fischer-Lexikon liefern. ${ }^{8}$ Für die Lehre in Köln spielen zudem die bereits in Zürich gehaltenen und verschriftlichten Vorlesungen eine zentrale Rolle; sie geben eine zentrale Basis für die spätere Lehre in Köln ab (vgl. Moebius 2015b; König im Druck; Moebius und Griesbacher im Druck). Die empirische Sozialforschung, für die König und die „Kölner Schule“ gemeinhin assoziiert werden, kommt in der Zürcher Zeit nur am Rande vor, die Zürcher Vorlesungen widmen sich hingegen insbesondere soziologiehistorischen, allgemeinsoziologischen bis hin zu soziale Probleme behandelnden Themen.

König ist durch seine Lehre und Publikationen für das Ordinariat in Köln bestens gerüstet: In der Züricher Zeit hat er ein eigenes Konzept von Soziologie entwickelt, dargelegt in Soziologie heute, verfügt über eine große Lehrerfahrung, hat bereits eine Schar von Schülern, eine Schriftenreihe und hat sich unter anderem ein breites Wis-

\footnotetext{
7 Im Folgenden wird auf Formulierungen und Abschnitte aus Moebius (2015a, S. 46ff.) zurückgegriffen. Im vorliegenden Beitrag wird ausführlicher auf die in Moebius (2015a) am Schluss behandelte Frage nach der Existenz einer „Kölner Schule“ näher eingegangen.

8 Zu den Schriften Königs siehe Alemann und Kunz (1992, S. 33 ff.).
} 
sen über die Allgemeine Soziologie, Familien-, Gemeinde- und Industriesoziologie sowie Soziologiegeschichte angeeignet. In den 1950er-Jahren führt er diese ungeheure Produktivität fort. ${ }^{9}$ König (1987, S. 14) versucht nun, ,die amerikanischen Forschungstechniken bekannt zu machen, aber nicht so sehr um der Theorie willen, sondern ausschließlich aus didaktischen Gründen, um die Lehre dieser Probleme zu erleichtern". ${ }^{10}$

Internationalisierung stellt ein wichtiges Element der Wirkung Königs in Köln dar. Dafür sind bereits die Jahre zwischen 1949 und 1953 von Bedeutung: Ein ehemaliger Freund aus dem Verlag „Die Runde“, Arvid Brodersen, Acting Head des Social Science Department bei der UNESCO, fragt ihn, ob er bei der Begründung einer internationalen Soziologiegesellschaft beteiligt sein möchte (König 1984, S. $159 \mathrm{ff}$.). So wird König einer der Mitbegründer der ISA (International Sociological Association, gegründet 1949), in den 1960er-Jahren ihr Präsident (1962-1966). Die internationalen Kontakte kann König 1952/53 während seiner ersten, von der Rockefeller Foundation finanzierten USA-Reise weiter ausbauen (vgl. König 1984, S. 198 ff. u. S. 279 ff.) Dabei kommt er auch unmittelbar mit der US-amerikanischen Sozialforschung in Berührung, mit der er sich bereits im Rahmen seiner Vorlesung „Einführung in die amerikanische Soziologie“ Anfang der 1940er-Jahre befasst hatte. Später folgen etliche Gastprofessuren in den USA, wobei König des Öfteren mit dem Gedanken spielt, die Bundesrepublik zu verlassen und in den USA zu bleiben, denn stets begleitet ihn die Wahrnehmung, als „Heimkehrer"11 nicht willkommen zu sein und seine schmerzvollen Erfahrungen der Emigration nicht gewürdigt und anerkannt zu wissen. Auch die restaurativen und antiintellektuellen Tendenzen der frühen Bundesrepublik und die Zeichen der Kontinuität zum NS-Regime befördern den dann in späteren Jahren immer deutlicher zutage tretenden Pessimismus und Skeptizismus (vgl. König 1984, S. 185 u. S. 189 ff.; von Alemann 2000, S. 335). Der Grund, dennoch in Deutschland zu bleiben, sei der Wunsch gewesen, ,die neue Generation im demokratischen Sinne zu erziehen“, so König (1989, S. 121). Dazu gehört auch für ihn, seine „Schüler“ zu Forschungsaufenthalten im Ausland zu ermuntern, was letztendlich zu einer verstärkten Professionalisierung der empirischen Orientierung der Kölner Soziologie führte.

Die Kölner Professur läuft zu Beginn hingegen beschwerlich an. Nicht nur, dass König noch bis Anfang der 1950er-Jahre zwischen Zürich und Köln hin und her pendelt. Am Institut lässt Leopold von Wiese nur schwer von seinen Ämtern los (vgl. König 2000, S. 68 ff.), ja ist sogar bestrebt, die Kölner Zeitschrift nicht an König,

\footnotetext{
9 Dies zeigt sich auch auf dem Feld der Netzwerke anhand der Briefwechsel, die ab 1957 an Zahl enorm zunehmen.

10 Weiter heißt es (König 1987, S. 16): „Alles das nur, um die grob vereinfachende Meinung zurückzuweisen, ich hätte die US-amerikanische Soziologie in Deutschland eingeführt; das war in Wahrheit schon viel früher erfolgt. Wohl aber beanspruche ich, als erster ein gutes Kompendium der empirischen Forschungstechniken herausgebracht zu haben.“ Die „Amerikanisierung“ ist bei König ebenfalls schon viel früher zu verorten, genauer gesagt in dem nicht zuletzt aufgrund des durch die Zeitschrift Sociologus vermittelten Interesses an der Chicago School (vgl. Albrecht 2013, S. 400). Gemeint ist Richard Thurnwalds Zeitschrift für Völkerpsychologie und Soziologie (1932/1933 und dann nach dem Krieg mit dem Obertitel Sociologus). Nicht zufällig erinnert der Titel an die KZfSS.

11 Vgl. dazu auch Schütz (2002, S. 104).
} 
sondern an Horkheimer und Adorno zu übergeben. Dadurch nimmt die Beziehung zu von Wiese Schaden. König ist weiterhin gewillt, in Zürich zu bleiben und hofft auf eine mögliche, in Aussicht gestellte Berufung nach Frankfurt. Als diese und damit verbunden auch die Verhandlungsoption mit Zürich scheitert, da die Züricher die Berufungsangelegenheit als Lüge auffassen (vgl. Zürcher 1995, S. 270 ff.), fällt 1953 endgültig die Entscheidung und König zieht mit der Familie nach Köln - von ihm als eine Art zweite Emigration empfunden (vgl. König 1989, S. 126; Lepsius 2006, S. 427).

König ist bestrebt, die Soziologie nicht nur von der kritischen Theorie der Frankfurter Schule, sondern auch von Schelskys (1959, S. 95 ff.), ,transzendentaler Theorie der Gesellschaft" abzugrenzen und versucht, in Köln eine Soziologie als dezidiert empirisch orientierte Wissenschaft aufzubauen und $\mathrm{zu}$ vermitteln, die er ganz in der Tradition Auguste Comtes und der Durkheim-Schule (und auch gegen ,rechte“ Tendenzen gewandt) kritisch-reformerisch als aufklärerisches Mittel für eine demokratische Gestaltung der Gesellschaft betrachtet. Dabei wendet er sich auch gegen die eigene, in der Zwischenkriegszeit vertretene geisteswissenschaftlich-hermeneutische Orientierung, gegen „Denk- und Argumentationsmuster“, die er als wesentlich für den Erfolg des Nationalsozialismus ansah (Klein 2014, S. 571; Wehler 2006, S. 47 f.). Lepsius (2017, S. 81) beschreibt Königs Position als diejenige eines „Promotor einer Soziologie als empirischer Einzelwissenschaft mit betonter Frontstellung gegen Sozialphilosophien rechts- oder linkshegelianischer Provenienz“.

Es lassen sich 5 Eckpunkte des König'schen Programms ausmachen, die nach Clemens Albrecht alle in einer ,älteren Kontinuitätslinie“ stehen, das heißt, bereits Ende der 1920er- und 1930er-Jahre entwickelt wurden, sodass die 1950erJahre ,kein Neuansatz, sondern ein Wiederauflegen der 1920er- und 1930er-Jahre“ darstellen, ,freilich in einer historisch-politischen Lage, die die Anerkennungschancen des ganzen Programms potenziert hatte" (Albrecht 2013, S. 389). Die Eckpunkte seiner Soziologie sind die „,struktur-funktionalistische Ethnologie“, „französische Theorie“, ,amerikanische Sozialforschung“, „moralistische Gegenwartswissenschaft" (Albrecht 2013, S. 387), hinzu kommt die breite Tradition der deutschen Soziologie der Zwischenkriegszeit. ${ }^{12}$ Von Königs „Programm“ ist es besonders die empirische Sozialforschung, mit der König und die Kölner Soziologie in den Auseinandersetzungen mit den anderen soziologischen Denkschulen und in der Folgezeit (meist ausschließlich) assoziiert werden. Nach Erwin Scheuch (2001, S. 144) gilt König in den 1950er-Jahren ,als der große Übermittler einer empirischen Sozialforschung auch quantitativer Art - obgleich er mit Statistik für seine eigenen Arbeiten nicht viel anfangen konnte“. Dabei spielt immer die Durkheim-Schule und insbesondere die US-amerikanische Soziologie und empirische Sozialforschung eine zentrale Rolle, die er zu Beginn der 1950er-Jahre auch in seinen Seminaren - u. a. neben der Familiensoziologie, der Soziologiegeschichte oder der Wirtschaftssoziologie - lehrt.

\footnotetext{
12 Diesen Hinweis auf die Tradition der Zwischenkriegszeit, wie sie sich etwa im berühmten Handwörterbuch der Soziologie von Alfred Vierkandt (1931) widerspiegelt, haben wir von Matthias Bös, dem dafür herzlich gedankt sei. Dazu passt auch, dass König 1982 eine gekürzte Studienausgabe dieses Handwörterbuchs herausgibt.
} 
Ganz in der Tradition der Durkheim-Schule verbindet König empirische Sozialforschung mit der Hinwendung zur Analyse konkreter gesellschaftlicher Problemlagen. Seine erste Kölner Vorlesung handelt dementsprechend 1949/50 von den „Gegenwartsproblemen der Soziologie nach dem Zweiten Weltkrieg“. Die zur Analyse der Probleme eingesetzten Forschungstechniken seien dabei sekundär und sollten von der Sache her entschieden werden (König 1998a, S. 147). Alles andere bezeichnet er als „Fliegenbeinzählerei“, „Forschungstechnokratismus“ oder „Klempnermeisterei“ (König 1988, S. 156) und einen tendenziellen gefährlichen Wirklichkeitsverlust der Soziologie. Königs Impuls, die empirische Sozialforschung insbesondere quantitativer Art so vehement in den Mittelpunkt seiner Bestrebungen im Aufbau der bundesrepublikanischen Nachkriegssoziologie zu stellen, obwohl er selbst diese Methoden nicht anwendet, stammt ,aus dem Willen zur Veränderung, der sich aus gehäuften existenziellen Unklarheiten, welche die Orientierung immer mehr belasten, entwickelt“ (König 1998a, S. 145). In seinen Augen bedürften die Deutschen in erster Linie wieder eines Wirklichkeitsbezugs. Um diesen herzustellen, fokussiert sich König auf die Vermittlung und Institutionalisierung der empirischen Sozialforschung sowie deren konsequente Anwendung auf die sich weiter ausdifferenzierenden und verändernden gesellschaftlichen Problemlagen (Familie, Gemeinde/Stadt-Verhältnis, soziale Mobilität, Jugend, Industrie etc.). Sozialforschung avanciert für ihn zur zentralen Methode der Problemanalyse und der reeducation der Deutschen. Steht hinsichtlich der bundesrepublikanischen Gesellschaft hierbei der kritische Wille zur ,aktiven Umformung der gegebenen Verhältnisse“ (König 1998a, S. 144) im Vordergrund, so ist zum anderen die quantitative Sozialforschung im Hinblick auf die sich seit den 1950er-Jahren verschärfenden Positionskämpfe um Deutungs- und Repräsentationsmacht im soziologischen Feld auch ein probates Kampfmittel gegen Adorno und Schelsky (vgl. König 1998a, S. 141 ff.). ${ }^{13}$

\subsection{Institutionalisierungsprozesse: Institut, Zeitschrift und Publikationen}

Grundlegungen für den Institutionalisierungsprozess der „Kölner Schule“ finden wir bereits vor Königs Ankunft in Köln. Am 4. Dezember 1947 wurde das 1919 geschaffene „Forschungsinstitut für Sozialwissenschaften“ in Köln (vgl. von Alemann 1981, S. 349; Gorges 1986, S. 97 ff.; Kaesler 1997, S. 235; Schad 1972, S. 49 ff.), das im Zuge des Nationalsozialismus am 31. März 1934 geschlossen worden war (vgl. Klingemann 1988, S. 79 ff.; Pinn und Nebelung 1990, S. 189), auf Betreiben von Leopold von Wiese und Christian Eckert als „Forschungsinstitut für Sozialund Verwaltungswissenschaften“" wieder neu eröffnet. ${ }^{14}$ Wie bereits bei der früheren

\footnotetext{
13 Siehe auch Scheuch (1996, S. 209). Diese Kämpfe können hier nicht en detail wiedergegeben werden; wir verweisen dazu auf die Darstellung in Moebius (2015a, S. 9 ff., 2017a sowie Scheuch 2001, S. 150ff.).

14 Zwischenzeitlich bestand ein von den Nazis gegründetes Forschungsinstitut des deutschen Sozialismus. Von Wiese setzte nach einem kurzen USA-Aufenthalt seine Lehre und Forschung als Ordinarius am Soziologischen Seminar der Universität fort (vgl. Klingemann 1988, S. 86f.). Die folgenden Angaben beruhen auf einem Bericht des Kölner Seminars für Soziologie aus dem Jahr 2000, anlässlich des 30. Kongresses der Deutschen Gesellschaft für Soziologie (26.-29. September 2000). Der Bericht trägt keine Autorenschaft und wird im Folgenden zitiert als „Bericht 2000“. Siehe zur Geschichte der Soziologie in Köln auch Knebelspieß und Moebius (2019; in diesem Heft).
} 
Einrichtung in der Zwischenkriegszeit (vgl. von Wiese 1957, S. 52; von Alemann 1981, S. 349 f.; Gorges 1986, S. 100 ff.) untergliederte sich auch das Institut der Nachkriegszeit in 3 Bereiche, in eine soziologische (Leopold von Wiese), eine sozialpolitische (Gerhard Weisser) und eine sozialrechtliche (Hans-Carl Nipperdey) Abteilung. Die durch von Wiese ins Leben gerufenen Kölner Vierteljahrshefte für Sozialwissenschaften wurden 1948 als Kölner Zeitschrift für Soziologie. Neue Folge der Vierteljahrshefte für Soziologie neu herausgegeben (vgl. Dreier 2017; Moebius 2017b). ${ }^{15}$

René König konnte hier anknüpfen, setzte aber andere Schwerpunkte, auch weil er die formale Soziologie von von Wiese sowie dessen Zurückhaltung in der Aufklärung über das NS-Regime äußerst kritisch betrachtete. König trug unter anderem zur Professionalisierung des Fachs in Köln dadurch bei, indem er Abteilungen zur Meinungs-, Konsum- und Verkehrsforschung begründete (vgl. von Alemann 1999, S. 84). Nach diesen Gründungen hielt er sich, wie von Alemann berichtet (von Alemann 1999) aus diesen Abteilungen weitgehend heraus. Damit ist bereits angedeutet, dass die „Kölner Schule“ trotz der zentralen Rolle der Gründungsfigur keine „,KönigSchule“ darstellt (siehe auch die späteren Ausführungen zur teilweise nur partiellen Weiterführung der kognitiven Leitideen). Daneben wurde die Neuausrichtung und Institutionalisierung der Kölner Soziologie auch durch Königs internationale Ausrichtung gestärkt (siehe dazu die Ausführungen in Abschn. Charismatischer Stifter der Leitideen: René König). Neben seinen Institutionalisierungs- und Professionalisierungsleistungen versuchte König im Sinne eines ,aktiven und realistischen Humanismus“ (König 1973, S. 11) und eines ,public intellectual“, die Soziologie zu ,popularisieren“ (König 1973, S. 9) und sie durch Vorträge, Radiobeiträge oder Zeitungsartikel publizistisch in die Öffentlichkeit zu bringen (vgl. Klein 2006, S. $406 \mathrm{ff}$.). Das diente in seinen Augen sowohl der Information, der Orientierung als auch der Aufklärung der Gesellschaft. ${ }^{16}$

\subsubsection{Zeitschrift: Kölner Zeitschrift für Soziologie und Sozialpsychologie}

1955 übernahm König von Leopold von Wiese die Herausgabe der Kölner Zeitschrift für Soziologie und benannte sie um in Kölner Zeitschrift für Soziologie und Sozialpsychologie (KZfSS). ${ }^{17}$ Zusätzlich führte König noch die Sonderhefte und Schwerpunkthefte der KZfSS ein, die teils neue Themengebiete erschlossen oder wiederbelebten, teils soziologisch auf drängende gesellschaftliche Problemlagen einzugehen und sie aufzuklären versuchten. ${ }^{18}$ Neben der Publikationsmöglichkeit in der Zeit-

\footnotetext{
15 Von Wiese war es auch, der bereits 1946 mit Unterstützung des US-HICOG-Offiziers und guten Kenner des deutschen Wissenschaftssystem Edward Y. Hartshorne (vgl. Tent 1998) die DGS wiederbegründete (vgl. von Wiese 1959, S. 17) und deren erster Nachkriegspräsident wurde.

16 In den folgenden Ausführungen zu den Publikationen wird dabei bereits die Rolle weiterer soziologischer Akteure deutlich. Im Detail gehen wir aber auf die Schüler erst in Abschn. Bindung weiterer soziologischer Akteure ein.

17 Vgl. zur KZfSS und ihren Sonderheften Dreier (2017, im Druck).

181956 erschien das erste, von König herausgegebene Sonderheft über Soziologie der Gemeinde (mit Beiträgen unter anderem von Nels Anderson oder Renate Mayntz), ein Jahr später das von König und Heintz besorgte Sonderheft über Jugendkriminalität, 1958 eines über Medizinsoziologie (hrsg. von König und
} 
schrift dienten auch die Sonderhefte den Jüngeren, die sie oft mit herausgeben durften, der korporativen Identitätssicherung der Kölner Soziologie. Natürlich wirkte die Zeitschrift auch als gate keeper, wobei sich König aber weitgehend dem wissenschaftlichen Ethos der Offenheit für andere Perspektiven verpflichtet fühlte. ${ }^{19}$ Wie etwa die Sonderhefte zeigen, existierte dort eine breite Palette an Themen. Auch wenn König und seine Mitherausgeber sicherlich darauf geachtet haben, dass die Themen auch immer empirisch gesättigt abgehandelt wurden, so könnte man dennoch einwerfen, dass die von Schule, Sprache, Sozialgeschichte bis hin zu Ethnologie reichende thematische Vielfalt der Sonderhefte keine alleinige Reduzierung der Kölner Soziologie auf einen Kern namens „empirische Sozialforschung“ erlaube. Zwar stieg mit König als alleinigem Herausgeber von 1955 bis 1975 ,der Anteil empirischer Arbeiten" um ein 3faches an (Krekel-Eiben 1990, S. 152; vgl. auch Lüschen 1979), aber verglichen mit anderen Zeitschriften relativierte sich das ein wenig; im Vergleich zur 1949 erstmals erscheinenden Sozialen Welt und der ab 1972 gegründeten Zeitschrift für Soziologie hat die KZfSS maximal gesehen nicht so viele empirische Beiträge veröffentlicht wie jene (vgl. Krekel-Eiben 1990, S. 152).

Insofern könnte man mit Blick auf die Zeitschrift und auf die Frage nach einer „Kölner Schule“ bis hier festhalten: Es lässt sich, wenn überhaupt, ein anderer Kern der Kölner Nachkriegssoziologie als allein die empirische Sozialforschung ausmachen: Eine von Königs breitem Programm, interdisziplinärem Wissen und Interesse ausgehende, empirisch gesättigte, problemzentrierte Ausdifferenzierung und damit Entprovinzialisierung und Professionalisierung der bundesrepublikanischen Soziologie als Krisenwissenschaft, die sich in der Bildung von Bindestrichsoziologien, der Setzung soziologischer Forschungsstandards sowie durch zahlreiche Lehrstuhlbesetzungen von Königs Schülern so konsolidiert hat, dass das Modell der empi-

Tönnesmann, mit Beiträgen u. a. von Parsons und Uexküll), 1959 gibt Heintz ein Sonderheft über Soziologie der Schule heraus, 1961 folgt ein von Glass und König verantwortetes Heft über Soziale Schichtung und soziale Mobilität, in dem nun verstärkt neben Heintz auch andere Schüler Königs vertreten sind. 1962 ein Heft über Religionssoziologie (hg. von Goldschmidt und Matthes), 1963 eines über Max Weber zum Gedächtnis (hrsg. von König und Winckelmann), Heft 81964 zur Soziologie der DDR (hrsg. von Ludz), 1965 zur Soziologie der Wahl (hrsg. von Scheuch und Wildenmann), 1966 Kleingruppenforschung und Gruppe im Sport (hrsg. von Lüschen), 1967 zur Rechtssoziologie (hrsg. von Hirsch und Rehbinder), 1968 Militärsoziologie (hrsg. von König, Roghmann, Sodeur, Ziegler), 1969 Entwicklungssoziologie (hrsg. von König, Albrecht, Freund, Fröhlich), 1970 Familiensoziologie (hrsg. von Lüschen und Lupri), 1971 Soziologie der Sprache (hrsg. von Kjolseth und Sack), 1972 Soziologie und Sozialgeschichte (hrsg. von Ludz), 1974 Künstler und Gesellschaft (hg. von König und Silbermann), 1975 Wissenschaftssoziologie (hrsg. von König und Stehr), 1977 Soziologie und Sozialpolitik (von Ferber und Kaufmann), 1978 Soziologie des Alltags (hrsg. von Hammerich und Klein), 1979 Deutsche Soziologie seit 1945 (hrsg. von Lüschen), 1980 Wissenssoziologie (hrsg. von Stehr und Meja), 1981 Soziologie in Deutschland und Österreich 1918-1945 (hrsg. von Lepsius), 1982 Industriesoziologie (hrsg. von Schmidt, Braczyk und Knesebeck), 1983 Gruppensoziologie (hrsg. von Neidhardt), 1984 Ethnologie als Sozialwissenschaft (hrsg. von Müller, König, Koepping und Drechsel), 1986 Kultur und Gesellschaft (hrsg. von Neidhardt, Lepsius und Weiß). Bereits beim letztgenannten Heft war König nicht mehr mit einem Artikel beteiligt, es handelt sich um eine Festschrift zum 80. von König. Die frühen Sonderhefte erreichten meist mehrmalige Auflagen.

19 Was vielleicht auch eine Art Strategie sein kann, um andere Zeitschriften klein zu halten. Zumindest hatte König auch Angst vor alternativen Zeitschriften, wie ein Brief an Scheuch vom 25.02.1971 anlässlich der Gründung des Mitteilungsblattes „Soziologie“ der DGS vermuten lässt, in dem König anbietet, Mitteilungen und Nachrichten der DGS in der KZfSS abzudrucken, womit ein eigenes Mitteilungsblatt überflüssig wäre (DGS-Akten im Sozialwissenschaftlichen Archiv Konstanz, Signatur DE-SAK-B1-3616). 
risch fundierten Soziologie mit Theorien mittlerer Reichweite zum selbstverständlichen, paradigmatischen oder mainstreamartigen Modell der Soziologie hierzulande schlechthin entwickelte (vgl. Sahner 1992, S. 256) - wobei der anfänglich sozialaufklärerische und gesellschaftskritische Impetus von König mitunter dabei oft auf der Strecke blieb. Die empirische Sozialforschung fällt bei dieser Auffassung einer „Kölner Schule“ nicht heraus, sie ist durchaus ein Kennzeichen der Schule, das nachträglich im Kampf um Repräsentationsmacht der konkurrierenden Schulen als ihr ,branding“ ge- oder missbraucht wurde, sie ist aber unserer Definition nach nicht das wesentliche Kriterium der von König initiierten „Schule“.

Wie die Vorbemerkung zur ersten von ihm herausgegebenen Ausgabe der KZfSS zeigt, hatte König bereits 1955 ein recht klares Bild davon, welche Themen und gesellschaftlichen Problembereiche (auch noch) in Zukunft Relevanz beanspruchen, er nennt etwa neben Gemeindesoziologie die Gruppensoziologie, Industriesoziologie, soziale Schichtung und Mobilität, Weltgesellschaft, politische Soziologie, Entwicklungssoziologie etc. (vgl. König 1998b, S. 106f.). Die von ihm forcierte problemzentrierte Ausdifferenzierung, die sich später in der Bildung Spezieller Soziologien institutionell bemerkbar machen wird, ist, so unsere These, darum auch weniger als ein zufälliges Ausfransen, sondern vielmehr als der bewusst vertretene, wesentliche Kernbestandteil der von König auf den Weg gebrachten Soziologie in Köln, der „Kölner Schule“, anzusehen.

\subsubsection{Publikationen: Fischer-Lexikon, Handbuch der empirischen Sozialforschung}

$\mathrm{Zu}$ einer Schule gehören neben einem charismatischen Lehrer und einer Zeitschrift, wie oben erwähnt, auch markante identifikatorische Publikationen. Im Falle der „Kölner Schule“ werden sie zum einen von König direkt verfasst und zum anderen zentral von ihm angestoßen. Sie legen gemeinsam mit den Instituten und institutionellen Verflechtungen, der Lehre, der Zeitschrift und der Anbindung von Schülern das Fundament der Kölner Soziologietradition.

Die ersten zentralen Anstöße in Richtung der weiteren Professionalisierung der Nachkriegssoziologie anhand der Implementierung und Institutionalisierung der empirischen Sozialforschung gibt König bereits 1952 mit der Herausgabe von Praktische Sozialforschung. Das Interview. Formen - Technik - Auswertung, dem ersten zentralen deutschsprachigen Methodenwerk dieser Zeit; der von dem LazarsfeldMitarbeiter Max Ralis, der 1953 bei König promovierte, ${ }^{20}$ initiierte (vgl. Ute Scheuch 2008, S. 111) Sammelband ${ }^{21}$ propagiert das Interview als den „Königsweg“ der Sozialforschung und stellt eine deutsche Variante des Programms „der Empirical Social Research [dar], das in den 1930er- und 40er-Jahren durch Paul Lazarsfeld, Robert K. Merton und ihre MitarbeiterInnen an der Columbia University entwickelt wurde und in den USA rasch Verbreitung fand. ... [Z]um Großteil handelt es sich um Auszüge aus Lehrunterlagen des von Lazarsfeld und Merton geleiteten Bureau of

\footnotetext{
20 Als Anhang zu diesem Beitrag fügen wir eine von Michael Klein erstellte Liste der von René König betreuten Promotionen bei, mit herzlichem Dank an Michael Klein.

21 Als Mitarbeiterstab der ersten Auflage fungierte Königs Züricher Assistent Peter Heintz und dessen Frau Susi Heintz.
} 
Applied Social Research (BASR). ... Die Einleitung Königs zeigt eine große Nähe zur Forschungshaltung der Columbia Tradition, fokussiert aber deutlicher als jene auf Hypothesenprüfung“ (Ploder 2017, S. 737).

Auszüge aus der Vorlesung zur amerikanischen Soziologie aus dem Wintersemester 1943/44 in Zürich unterstützen diese Einschätzung: „Ohne soziologische Forschung ist nämlich Statistik a priori unfruchtbar - dies die auch für Europa bedeutsame Grundeinsicht der amerikanischen Soziologie. Die Statistik ist nur eine Methode ... zur Einsicht in kleinere und größere soziale Zusammenhänge, aber die quantifizierende Methode wird erst dann auf Erfolg rechnen können, wenn sie sich auf eine vorgängige qualitative Analyse dieser Erscheinungen stützen kann.“ (König im Druck).

1957 erscheint eine 2. Auflage. Bei der 1. Auflage werden Wilhelm Brepohl, Max Ralis und der von Wiese-Schüler Karl G. Specht als Mitherausgeber genannt, bei der 2. Auflage sind es die König-Schüler Dietrich Rüschemeyer und Erwin Scheuch. 1956 erscheint unter Mitherausgabe von Peter Heintz und Erwin Scheuch Praktische Sozialforschung II. Beobachtung und Experiment, ${ }^{22}$ in deren Einleitung König, was oftmals übersehen wird, die Untrennbarkeit von qualitativer und quantitativer Sozialforschung betont. Dass die Schüler mit auf dem Titelblatt stehen, wie König dies veranlasste, war damals eher unüblich und bezeugt seine Förderungsbereitschaft junger Wissenschaftler.

1958 publiziert König das in viele Sprachen übersetzte Soziologie-Lexikon im Fischer-Verlag, das mit über 400.000 Exemplaren zu einem der meistverkauften wissenschaftlichen Fachbücher avancierte und zur Popularisierung der Kölner Soziologie wesentlich beitrug. An dem Lexikon, das von den erwähnten Zürcher Vorarbeiten profitiert, sind neben König auch zahlreiche „Schüler“ und Kollegen beteiligt: Erwin Scheuch, Dietrich Rüschemeyer, M. Rainer Lepsius, Karl Martin Bolte, Alphons Silbermann, Emilio Willems, Rolf Ziegler sowie in späteren Neuausgaben auch Prodosh Aich, Klaus Roghmann, Paul Drewe, Dieter Fröhlich, Hans-Joachim Hummell, Maria Mayser, Karl-Dieter Opp, Horst Schmelzer, Günter Albrecht, Gerd Christiansaen, Manfred Güllner, Wolfgang Kaupen, Michael Klein sowie Franz-Josef Stendenbach (vgl. König 1967, S. 7). Dabei schont König seine Schüler nicht. In deren Augen hat er die Tendenz, sie ,als Assistenten sehr zu belasten. Damit ist nicht gemeint, dass er seine Mitarbeiter für eigene Zwecke arbeiten ließ - wie das in deutschen Universitäten beim Ordinarienprinzip weit verbreitet war -, gemeint ist hier die Vielzahl der Projekte für das Institut, die König einfielen oder ihm von einem weltweiten Bekanntenkreis nahegebracht wurden“ (Scheuch 1996, S. 214).

Eine weitere Publikation, die zur Typisierung und Konstruktion einer „Kölner Schule“ beigetragen hat, ist das von Heinz Maus ${ }^{23}$ initiierte, seit 1962 erscheinende,

\footnotetext{
22 Vgl. zur ausführlicheren Vorstellung dieser Schüler Moebius (2015a, S. 80 ff.).

${ }^{23}$ Wie Oliver Römer aufgrund des Maus-Nachlasses festhält, lassen sich die „Ursprünge dieses Handbuchs ... anhand des Nachlasses von Heinz Maus bis in die frühen 1940er-Jahre zurückverfolgen. Dies verdeutlicht der Briefwechsel mit Andreas Walther, in dem Maus bereits auf die Notwendigkeit eines solchen ,Methodenmanuals‘ zu sprechen kommt. ... Im Maus-Nachlass erhaltene Briefbögen des EnkeVerlags und Korrespondenzen zeigen, dass die ursprünglichen Herausgeber dieses für die Entwicklung der deutschsprachigen Soziologie so ungemein wichtigen Handbuchs ursprünglich Maus und der WieseAssistent Karl-Gustav Specht waren“ (Römer 2018, S. 192, FN. 14).
} 
mehrbändige Handbuch der empirischen Sozialforschung ${ }^{24}$. Das 15-bändige Handbuch (15, wenn man $\mathrm{Bd}$. 3a und $3 \mathrm{~b}$ als eigenständige Bände zählt) enthält nicht nur für die westdeutsche empirische Sozialforschung wegweisende Beiträge, sondern ist selbst ein Zeichen einer verstärkt beginnenden, professionalisierten Ausdifferenzierung des Fachs. Neben Geschichte, Wissenschaftstheorie, Methoden, Techniken und Forschungsansätzen behandeln die Bände Themen wie Soziale Schichtung und Mobilität, Jugend, Familie, Alter, Beruf, Industrie, sozialer Wandel, Organisation, Militär, Großstadt, Gemeinde, Massenkommunikation, Freizeit, Konsum, Wahlverhalten, Vorurteile, Kriminalität, Sprache, Künste, Religion und Medizin. Wie bereits beim Lexikon sind - neben renommierten Sozialwissenschaftlern aus dem In- und Ausland - ebenfalls zahlreiche (teilweise dann auch ehemalige) Kölner an diesem Großprojekt beteiligt, u. a. Erwin Scheuch, Helmut Zehnpfennig, Peter Heintz, Alphons Silbermann, Rolf Ziegler, Hansjürgen Daheim und Fritz Sack.

König ist sich vollkommen klar darüber, dass er mit den Bänden des Handbuchs zu dem, was wir den Kern der „Kölner Schule“ bezeichnen (problemzentrierte, empirisch orientierte Ausdifferenzierung und damit Professionalisierung der westdeutschen Nachkriegssoziologie) wesentlich beiträgt. Dies geschieht nicht unreflektiert und im vollen Bewusstsein der Historizität des jeweiligen Gegenstands. Neben den Vorteilen einer solch spezialisierenden Ausdifferenzierung sieht er auch ganz deutlich die negativen Tendenzen und Gefahren einer Spezialisierung. So schreibt er im Vorwort (König 1976, S. VII-XIV) der 2. Auflage des 5. Bands (Soziale Schichtung und Mobilität), dass das Handbuch gerade die ungewöhnlich große Differenzierung der Forschungsgebiete aufzeige und es zwar wichtig sei, dass zu bestimmten Zeiten gewisse Themen im Vordergrund stünden; die Bildung von „Bindestrich-Soziologien" tendiere jedoch gleichermaßen zu der Gefahr, an der historischen Wandelbarkeit der Gesellschaft vorbei zu gehen, ${ }^{25}$ ganz zu schweigen, dass dadurch - so Königs an die Kritische Theorie erinnernde Auffassung - der ,gesellschaftliche Gesamtzusammenhang “ aus dem Blick gerate. Deswegen plädiert er zwar für eine Spezialisierung, ohne jedoch ihren wesentlich pragmatischen Charakter aus den Augen zu verlieren:

So sollte man sich vor einer allzu weitgehenden Institutionalisierung solcher Spezialdisziplinen hüten und sie als das sehen, was sie sind: eine nützliche Konstellation von Konzepten, Methoden und Forschungstechniken zur Bearbeitung einer existentiell aufdringlichen Problematik, die man aber bereit sein muß, über Bord zu werfen, so wie neue existentielle Herausforderungen spürbar werden. Auch das verweist neuerlich auf den gesellschaftlichen Gesamtzusammenhang, den man nicht ,aufteilen“ oder ,zerlegen“ kann, sondern durch den man jeweils nur bestimmte situationsbedingte Schnitte legen kann, auf deren Oberfläche bestimmte Probleme sichtbar werden. Damit allein ist schon gesagt, daß es sich immer nur um Provisorien handeln kann, die für ein oder zwei

\footnotetext{
24 Mit dem Handbuch ist König dann über nahezu 2 Jahrzehnte durch Neuauflagen und Koordinierung der Autoren immer wieder kräftezehrend beschäftigt.

25 Entgegen der Vermutung der Ahistorizität, die zahlreiche Gegner empirischer Sozialforschung vorwerfen, betont König, dass diese gerade das historische Moment von Vergesellschaftung offenbar werden lasse (König 1979, S. 362).
} 
Generationen erleuchtend sind, dann aber ihre kognitive und wissenschaftliche Funktionalität verlieren. (König 1976, S. XIII) ${ }^{26}$

Wie in der KZfSS, zeigt sich auch in den Publikationen der Kern der problemzentrierten Ausdifferenzierung und das Setzen von Forschungsstandards der von König angeregten Kölner Soziologie. Mit der KZfSS, den Sonderheften, der seit 1966 begonnenen Reihe Kölner Beiträge zur empirischen Sozialforschung und angewandten Soziologie ${ }^{27}$, dem Soziologie-Lexikon und dem mehrbändigen Handbuch der empirischen Sozialforschung verfügen die Kölner über zentrale Eckpfeiler zur Absicherung, Institutionalisierung und Popularisierung ihrer soziologischen Positionen im Feld, die den Analysen Heinz Sahners zufolge bis Mitte/Ende der 1960erJahre durchaus eine homogene und das gesamte Feld prägende ,Schule“ der Kölner Soziologie erkennen lassen. ${ }^{28}$

Die Handbücher, Sonderhefte und das Lexikon sind nicht nur in der Forschung brauch- und anwendbar, sondern auch für die Lehre und verweisen auf Königs „systematische Verbindung von Forschung und Lehre“ (Klein 2014, S. 559).

Entsprechend der Wissenschaftspolitik des Landes Nordrhein-Westfalen wurde das „Forschungsinstitut für Soziologie“ großzügig mit „Mittelbaustellen“ (Assistenten) ausgestattet. Dies ermöglichte ihm [gemeint ist René König], die Verbindung von Lehre mit der Forschung nicht aus zufällig eingeworbenen Drittmittelprojekten herzustellen, sondern im bei Paul. F. Lazarsfeld entlehnten Geiste als „Institution“ zu kreieren. Schon zu Beginn der 1950er-Jahre sah er die Funktion der Forschungsinstitute für Soziologie in der Entwicklung und Vermittlung von Soziologie und dies wurde in der Tat konstitutiv für seine Art der Begründung der Soziologie ,,aus dem Geiste der Empirie“ im Deutschland der Nachkriegszeit. (Klein 2014, S. 559f.) ${ }^{29}$

\footnotetext{
${ }^{26}$ Oliver König und Michael Klein bringen Königs Position folgendermaßen auf den Punkt: „Daß mit dieser Ausdifferenzierung in Teil-Soziologien die Einheitlichkeit des Faches immer mehr schwand, erfüllte ihn allerdings auch mit Unwohlsein, da er mit dieser Entwicklung nicht in erster Linie eine Verfeinerung und Präzisierung soziologischer Theoriebildung, sondern weit eher einen neuen fachspezifischen Provinzialismus heraufziehen sah. Er wollte verbinden und nicht trennen." (Klein und Oliver König 1998, S. 12.).

${ }^{27}$ Die Kölner Beiträge zur empirischen Sozialforschung und angewandten Soziologie befassten sich mit zeitgenössischen Fragestellungen und der Anwendbarkeit von Forschungstechniken, zum Beispiel unter anderem mit Regional- und Stadtplanung, Kirchgang, Kommunalverfassung, Kommunikationsstrukturen, Stereotypen, Autoritarismus, Arbeitsprozesse, Verhaltensforschung, Interview, Führungsverhalten, Soziografie.

${ }^{28}$ Vgl. Sahner (1982, S. 63-127). Nach Sahners quantitativer Analyse ist die Kölner gemäß ihrer empirischen und theoretischen Ausrichtung sowie ihrer ,engen Identität zwischen Doktorvater und Schülerschaft“ (Sahner 1982, S. 126) gar die homogenste „Schule“ der westdeutschen Soziologie (Sahner 1982, S. 106).

${ }^{29}$ Im Gegensatz zu Schelsky und der Sozialforschungsstelle Münster/Dortmund ging es König mit dem Forschungsinstitut, so die Interpretation von Michael Klein, nicht nur um die ,empirische Einwirkung auf die gesellschaftliche und staatliche Entwicklung“, sondern um eine ,sinnkonstituierende Sicht" und „konstruktive Gestaltung“ der Wirklichkeit, in der „Entfaltung von eigenen Sichtweisen und Fragen“ in kritischer Distanz (Klein 2006, S. 404). Und: „Hier liegt der eigentliche Ursprung dafür, die ,Kölner Schule" mit der Etablierung der empirischen Soziologie in Deutschland zu assoziieren." (Klein 2014, S. 560).
} 


\subsection{Bindung weiterer soziologischer Akteure}

Während die Publikationen deutlich auf die Wirksamkeit der „Kölner Schule“ in der wissenschaftlichen Fachöffentlichkeit hindeuten, geht etwa Neidhardt davon aus, dass König hinsichtlich der allgemeinen Öffentlichkeit relativ wenig wirksam war (da waren Schelsky und Adorno in seinen Augen erfolgreicher), dafür war aber bei ihm die „kleine Öffentlichkeit des Hörsaals“ relevanter (Neidhardt 2006, S. 135). Der Hörsaal erscheint bei König tatsächlich als zentrales Wirkungsfeld, wenn wir uns mit der Frage der Bindung weiterer soziologischer Akteure befassen. Im Nachfolgenden skizzieren wir auf der einen Seite sein Verständnis von Lehre und gehen auf der anderen Seite auf die Wahrnehmung der Wirkung Königs als Lehrender bei seinen Schülern ein.

\subsubsection{Lehre bei René König}

René König betonte das dialogische Lehren, die intensive Vorbereitung der Lehre und die Lehre dann aber in freier Rede ohne Manuskript. Lässt sich aus diesem Anspruch allein die Wirkung Königs als Vortragender verstehen? Unseres Erachtens nicht. Seine Persönlichkeit, die sich als Vortragender entfaltete, ihn bei manchen Zuhörern gar als „Zauberer“ oder „Meister“ erscheinen ließen, ist vielschichtiger. Es gibt zahlreiche schriftlich vorliegende Erinnerungen von ehemaligen Studenten Königs, über die sich ein vielseitigeres Bild der Wirkung Königs als ,,Vortragspersönlichkeit" nachzeichnen lässt.

Rolf Ziegler sieht dabei vor allem Parallelen zu Émile Durkheim. König beschrieb Durkheims Lehre folgendermaßen: „Äußerlich trat diese schon hervor in der Art seines Vortrags: leidenschaftlich erregt floß der Strom seiner Rede, die trotz sorgfältiger (schriftlicher) Vorbereitung fast immer schöpferischer Improvisation entsprang. ... Sein leidenschaftliches Gefühl steht ganz und gar im Dienste der Sache. So allein konnte er dem strengsten wissenschaftlichen Vortrag den Nachdruck seherischer Prophetie verleihen, die schon aus seinem Angesicht ... zu seinen Schülern sprach. ... Allerdings suchte er ... die Erziehung Gleichgesinnter nicht zu erreichen durch billige Kathederprophetie, sondern einzig durch die Übermittlung einer methodischen Forschungsweise.“ (König 1978, S. 118). Nach Ziegler könnten diese Worte aber auch König selbst gegolten haben (zit. nach Ziegler 1998, S. 27 f.). König hatte eine große Leidenschaft für die Lehre (vgl. Klein 2014, S. 554).

Diese Leidenschaft übertrug sich. Im Überblick gesehen, waren alle seine Studenten - sofern sie sich schriftlich zu ihm geäußert haben - von René Königs Lehrfähigkeiten tief beeindruckt, insbesondere von seiner dadurch zum Ausdruck kommenden charismatischen Persönlichkeit (vgl. Atteslander 1992; Büschges 1992; Lepsius 1992; Scheuch 1992, 1998; Sack 2010; Daheim 1998; Zahn 1992; Ziegler 1992; Benninghaus und Stehr 1992; Heintz, nach Hoffmann-Nowotny 1992). Einige überzeugte König als moralische Persönlichkeit (Benninghaus und Stehr 1992), als Gegenpol zur historischen Last des Nationalsozialismus, was natürlich die jungen Studenten in Köln ab 1949 betraf, oder bereits in einzelnen Vorträgen in München und Köln davor. Andere waren begeistert von seinem enzyklopädischen Wissen (vgl. Lüschen 1992), seinen analytischen und didaktischen Fähigkeiten, Theorietraditio- 
nen, wie jene des Marxismus oder der französischen Soziologie, verständlich zu machen (vgl. Rüschemeyer 1996; Ziegler 1992). Andere waren von einem wichtigen Aspekt seines Programms für die Soziologie überzeugt: nämlich die Ausrichtung als empirische Wissenschaft, die entsprechend über ein ordentliches methodisches Handwerkszeug zu verfügen hatte. Wie er seine Studenten und Assistenten, und zwar bereits in Zürich, zu empirischen Projekten trieb, das machte die Soziologie für jene als empirische Wissenschaft bedeutsam, ja gab mit König dann von Köln aus den zentralen Antrieb zu einer dann doch dominanten empirischen Ausrichtung (man denke dabei an die Forschungsabteilungen, die Methodenlehrbücher und die Kölner Zeitschrift).

Neben seiner offenen Persönlichkeit, die so gar nicht dem zeitgenössischen Bild des Universitätsprofessors entsprach, spielten 1. seine Art Soziologie vorzutragen, 2. seine Betonung der empirischen Sozialforschung und 3. seine Neigung zum Moralisten die zentralen Rollen für die Begeisterung der Studierenden. Diese 3 Momente kommen auch sukzessive in seiner Biografie hervor. In der Züricher Zeit war es wohl vor allem die erste Eigenschaft und seine Offenheit, die seine ,Jünger“ anlockte. Aber auch die Anregung zu empirischer Sozialforschung begann zu dieser Zeit. Der Moralist trat hingegen stärker in Köln hervor und entfaltete sich dort angesichts der restaurativen Adenauer-Zeit. Er beeindruckte die deutschen Studenten mit klaren Wertüberzeugungen und konnte, dank seiner Biografie, seine moralischen Positionen glaubhaft einnehmen und vertreten. Doch nachhaltig etablierte er sich in Köln doch am meisten mit der Betonung und Forcierung der empirischen Sozialforschung, die insbesondere mit internationalem Blick vorangetrieben wird: ,Wohl alle jüngeren Soziologen, die in Köln studierten, sind durch ihn ,internationalisiert worden.“ (Lepsius 1979, S. 36).

Die Empirie lehrten jedoch vor allem seine Schüler. König hingegen ging es in der Lehre nicht um eine permanente Verfeinerung der Methoden, sondern ebenfalls insbesondere um eine problemzentrierte Sicht auf gesellschaftliche Phänomene und eine dafür notwendig interdisziplinäre Sichtweise. Scheuch (2001, S. 149): „Die Vorlesungen von René König zogen viele Studenten aus anderen Fächern an und bewog nicht wenige, zur Soziologie als Studienfach zu wechseln. Für diesen Erfolg war sein Eklektizismus mitverantwortlich. Die Vorlesungen verwoben ineinander Sozialgeschichte, Ethnologie, Sozialpsychologie und auch noch Soziologie im engeren Sinn.“

\subsubsection{Schüler}

Wie der knappe Blick auf die Publikationen gezeigt hat, fördert König bereits zu Beginn seiner Professur in Köln die jüngeren Mitarbeiter, indem er sie in die dann breit rezipierten Veröffentlichungen mit einbezieht. Auch die Schülerschaft Königs weist eine thematische Breite auf, die zunächst einmal nicht unmittelbar dafür spricht, die Kölner Soziologie allein nur mit empirischer Sozialforschung zu identifizieren oder mit „Positivismus“ gleichzusetzen, auch wenn dies im Distinktionskampf im soziologischen Feld der 1960er- und 1970er-Jahre en vogue war. Die alleinige Identifizierung der Kölner Soziologie mit empirischer Sozialforschung mag vor dem Hintergrund dieser Kämpfe im soziologischen Feld plausibel erscheinen, ins- 
besondere wenn man die insbesondere von Erwin K. Scheuch forcierte angewandte und empirische Soziologie als einzigen Maßstab nimmt. Dann wäre vielleicht Scheuch der eigentliche Begründer der „Kölner Schule empirischer Ausrichtung“. Diese Meinung kann man vertreten, aber aus unserer Perspektive beginnt die Kölner Nachkriegssoziologie und „Kölner Schule“ mit König, weil dieser dort in der universitären Soziologie erst die zentralen Weichen hin zur Stärkung und Institutionalisierung der Soziologie, eben auch der empirischen Soziologie gestellt hat. So konnte auch Scheuch erst in Köln durch König und dessen forcierte problemzentrierte, empirische Ausrichtung reüssieren.

König förderte Scheuchs Lehrmöglichkeit und ließ ihn Kurse in empirischer Sozialforschung abhalten. Ebenso vermittelte er ihm Auftritte im Rundfunk (Ute Scheuch 2008, S. 111 u. 121). 1953 bot ihm König eine Assistentenstelle an. 1956 promovierte Scheuch schließlich bei König und dem Statistiker Jakob Breuer über das Auswahlverfahren in der Sozialforschung. Ihre Anwendung bei Repräsentativ-Befragungen. Neben Scheuch gehörten zum Doktorandenseminar Anfang der 1950er-Jahre Höfer, Krapp, Büschges, Schneider, Scheele, Schmitz, Sieben und Rüschemeyer (vgl. Ute Scheuch 2008, S. 143). Scheuch profitierte nach eigenen Angaben sehr von Königs zahlreichen internationalen Beziehungen. Eine Stipendienvergabe der Rockefeller Foundation ermöglichte Scheuch 1959 einen längeren Aufenthalt in den USA, ,to study methodological aspects of survey methods in the social sciences with particular emphasis on the problems of scaling“", wie es in der Rockefeller-Akte heißt. ${ }^{30}$ Nach Köln zurückgekehrt und in den Methoden der quantitativen Sozialforschung bestens ausgebildet, gründete Scheuch 1960 zusammen mit Günter Schmölders das „Zentralarchiv für empirische Sozialforschung“. ${ }^{31}$ Ende 1961 wurde er mit einer Arbeit über „Skalierungsverfahren als Instrument der Sozialforschung“ in Soziologie habilitiert. Zuvor erhielt er im gleichen Jahr den Ruf nach Harvard, um dort für 3 Jahre als Dozent für Sozialpsychologie am Department for Social Relations zu lehren. Mit maßgeblicher Unterstützung durch König wurde Scheuch 1964 zunächst als Extraordinarius nach Köln berufen. Einen weiteren Ruf nach Berlin nutzte Scheuch in den Verhandlungen in Köln zur Umwandlung des Extraordinariats in ein Ordinariat für besondere Soziologie (Scheuch 1998, S. $248 \mathrm{ff}$.; Ute Scheuch 2008, S. 394). 1965 gründete er das Institut für international vergleichende Sozialforschung - ab 1968 in Institut für vergleichende Sozialforschung umbenannt - (1975 unter Scheuch und der neuen Lehrstuhlinhaberin Renate Mayntz dann Institut für angewandte Sozialforschung). ${ }^{32}$

\footnotetext{
30 Akte Erwin K. Scheuch, A 58391, Rockefeller Fellowship Cards, Rockefeller Archive Center, Kopie zur Verfügung gestellt von Christian Fleck.

311962 werden erstmalig die sozialwissenschaftlichen Projekte im deutschsprachigen Raum erhoben. 1980 ist das Zentralarchiv (ZA) an der ersten ALLBUS-Studie beteiligt (ALLBUS steht für Allgemeine Bevölkerungsumfrage der Sozialwissenschaften), wird 1985 das Zentralarchiv des ISSP (International Social Survey Programme) und 1986 zum Mitglied der GESIS (Gesellschaft Sozialwissenschaftlicher Infrastruktureinrichtungen). Nach Erwin Scheuch wird Wolfgang Jagodzinski 1993 Direktor des ZA. Zu den Projekten, Publikationen und MitarbeiterInnen des ZA siehe Bericht (2000, S. $39 \mathrm{ff}$.).

32 Neben den Soziologie-Lehrstühlen existierten in Köln noch andere sozialwissenschaftliche Forschungseinrichtungen wie das Seminar für Sozialpolitik und Genossenschaftswesen sowie das Institut für Selbsthilfe (Ludwig Heyde, Gerhard Weisser). „Dieses Nebeneinander sehr unterschiedlicher Vorstellungen von Sozialwissenschaft und Sozialforschung machte in Köln das Klima aus, das von prominenten Studierenden
} 
Von König initiiert war es insbesondere Scheuch, der die Kollegen und die Doktoranden in die Praxis empirischer Sozialforschung einführte (vgl. Atteslander 2008, S. 426) und die Professionalisierung der empirischen Sozialforschung in Deutschland durchführte. ${ }^{33}$ Man kann deshalb sagen, die „Kölner Schule“ baute unter Federführung von Scheuch ihr Element der empirischen Sozialforschung weiter aus und professionalisierte dieses zunehmend, sodass die Kölner Soziologie mit ihrem Kern der problem- und empiriezentrierten Ausdifferenzierung nicht nur Stichwortgeber zahlreicher empirisch ausgerichteter Bindestrichsoziologien wurde, sondern die empirischen Forschungsmethoden nun selbst zu einer Art Speziellen Soziologie avancierten. So gründete Scheuch schließlich eine eigene Methodensektion in der DGS. Diesen Prozess erachtete König zunehmend für problematisch, weil er die Gefahr des Wirklichkeitsverlusts eines „Forschungstechnokratismus“ und selbstbezüglichen Methodisierens witterte. Rolf Ziegler erinnert sich an diese Kritik Königs und bekräftigt nochmal, dass es diesem nicht in erster Linie um die Methoden ging, sondern um empirisch unterfüttertes Problembewusstsein, das auch im Blick auf die Schüler für unterschiedliche Sichtweisen und Theorieorientierungen weitgehend offen war (sofern sich diese nicht im geschichtsphilosophischen oder individualistischreduktionistischen Bereich befanden):

René König hat sich immer gegen das plumpe Stereotyp gewandt, die „Kölner Schule" sei der von ihm betriebene Import der amerikanischen Sozialforschung, die letzten Endes zu nichts anderem führe als theorieloser Fliegenbeinzählerei, spitzfindiger Methodenakrobatik und forschungstechnischem Leerlauf. Wo er solche Tendenzen spürte, hat er sie selbst schonungslos gegeißelt und verspottet. ... Die Warnung an die „Jünglinge“, richtige Soziologie zu machen und wirkliche Probleme zu behandeln, war auch für jeden von uns unüberhörbar. Im Übrigen waren auch unter Königs jüngeren Mitarbeitern der 1960er-Jahre durchaus verschiedene inhaltliche Positionen vertreten: z.B. die ,strengen“ Parsonianer Heidrun und Wolfgang Kaupen, der während seines Aufenthaltes an der University of Chicago zum Symbolischen Interaktionismus „konvertierte“ Fritz Sack oder die „Reduktionisten“ Hans-Joachim Hummell und Karl-Dieter Opp. (Ziegler 2010, S. 56).

Verbindet man mit der „Kölner Schule“, wie wir das vorschlagen, eine Professionalisierung und Institutionalisierung der Soziologie im Sinne der vorangetriebenen problemzentrierten Ausdifferenzierung, so spiegelt sich das auch in den von König betreuten Dissertationen wider, die von einer enormen Vielfalt und Offenheit der Themen geprägt sind, die von ethnologischen, literatursoziologischen bis hin zu industriesoziologischen oder Wahlanalysen reichen und die auf Königs großen Bildungshorizont und die Bandbreite seiner Interessens- und Wissensgebiete verweist. Die im Anhang dieses Beitrags angefügte Liste der bei König angefertigten

beschrieben wurde ... . Verglichen mit der Forschungslandschaft an anderen Hochschulstandorten wurde in Köln von Scheuch und König recht gezielt ein institution building betrieben“ (Weischer 2004, S. 94.). Zum ,,institution building“, zu dem das ZUMA (Zentrum für Umfragen, Methoden und Analysen) oder GESIS zählt (Scheuch 1998, S. 255 ff.).

33 Siehe auch die für die empirische Sozialforschung wegweisenden Beiträge von Scheuch in dem von König herausgegebenen Handbuch der empirischen Sozialforschung. 
Dissertationen weist dabei eine so beträchtliche Zahl an Doktoranden auf, sodass hier nicht auf alle eingegangen werden kann. ${ }^{34}$ Ein knapper Blick auf Doktoranden und ihre Themen kann jedoch die problemzentrierte und ausdifferenzierte soziologische Ausrichtung der Anfangszeit dessen, was man „Kölner Schule“ nennen könnte, beleuchten. So finden sich Dissertationen aus den Bereichen der Ethno-, Religions-, Kunst- und Freizeitsoziologie bis hin zur Institutionen- und Rollentheorie. Die meisten sind empirisch orientiert, aber nicht nur. Manche behandeln ebenso Theorierichtungen oder Ideengeschichte wie etwa Dietrisch Rüschemeyers Arbeit über die Wissenssoziologie und dessen spätere Theorievermittlung Parsons ${ }^{35}$, Michael Oppitz' berühmt gewordene Studie über Lévi-Strauss, Jacob Taubes' Abendländische Eschatologie, Josef Guglers Dissertation über die französische Soziologie, Alfred Bellebaums Studie über Tönnies oder Wilfried Gerhards Arbeit über Ernst Troeltsch zeigen.

Peter Heintz, einer von Königs ersten Schülern, verfasste beispielsweise 1951 eine Monographie über Anarchismus und Gegenwart. 1957 war Heintz Mitherausgeber des 2. Sonderhefts der KZfSS zu Soziologie der Jugendkriminalität. Seine Vorlesungen behandelten Kulturanthropologie, Kriminalsoziologie, Technik, Sozialpsychologie, Vorurteilsforschung und Entwicklungssoziologie. Im Gegensatz zu Schülern wie Scheuch oder Peter Atteslander widmete er sich nicht dezidiert der empirischen Sozialforschung, etwas schematisch könnte man sagen, er repräsentierte eine der vielen anderen Seiten von Königs Soziologie, die vor dem Hintergrund der immer sichtbareren Forcierung der empirischen Sozialforschung in den Kölner Jahren oft in den Hintergrund gerieten. Aber natürlich soll das auch nicht darüber hinwegtäuschen, dass die empirischen Forschungsarbeiten wesentlich zum Kern der problemzentrierten Ausdifferenzierung gehören. So promovierten nicht nur Scheuch, sondern auch Schüler wie Günter Büschges, Walter Scheele oder Gerhard Kunz über Methodenfragen.

In den Anfangsjahren spielten relevante Themen der Nachkriegsgesellschaft wie Familie, Urbanisierung, Veränderung der Gemeinden, Industrieentwicklung, Betriebs- und Organisationssoziologie, soziale Schichtung sowie das durch das ,Wirtschaftswunder" steigende Konsum- und Freizeitverhalten eine zentrale Rolle in den Forschungsarbeiten.

Königs Aversion gegen die ,muffige und bigotte Atmosphäre des Adenauer-Regimes“ (König 1984, S. 179u. 185) schlug sich auch auf seine Schüler nieder oder wurde von diesen geteilt. Dies trifft allerdings nach Burkart Lutz (2000, S. 39) für einen großen Teil der soziologischen Nachkriegskohorte allgemein zu, deren Wunsch es gewesen sei, sich , aktiv und kritisch mit dieser dumpfen, stickigen, rückwärts-

\footnotetext{
34 Zentrale Schüler Königs waren neben Peter Heintz, Erwin K. Scheuch, Peter Atteslander, Dietrich Rüschemeyer unter anderem Fritz Sack, Hansjürgen Daheim, Hans-Joachim Hoffmann-Nowotny, Wolfgang Sodeur, Rolf Ziegler, Karl-Dieter Opp, Hans Joachim Hummell, M. Rainer Lepsius, Hans Peter Thurn, Dieter Fröhlich, Heine von Alemann, Gerhard Kunz, Heinz Sahner, Wolfgang Sodeur, Günther Lüschen, Michael Klein, Günter Albrecht, Klaus Allerbeck oder Kurt Hammerich.

35 Für die nächste Generation der „Kölner Schule“ ist Rüschemeyer neben König der Theorievermittler, wie Rolf Ziegler berichtet: „Für die Ausbildung in den Übungen und Seminaren waren vor allem die beiden Assistenten wichtig: Dietrich Rüschemeyer, der die theoretische Soziologie lehrte, und Erwin K. Scheuch, der die Methodenausbildung betreute“ (Ziegler 2010, S. 57).
} 
gewandten Atmosphäre der Adenauerschen Bundesrepublik in den fünfziger Jahren auseinanderzusetzen ...“. Wobei die Schulen sich auf ganz unterschiedliche Weise damit auseinander- und Akzente setzen. Kölner Studierenden der 1950er- und 1960er-Jahre war nach Hans-Joachim Hummell (1998, S. 311) ,die Konzeption einer Soziologie als positiver Einzelwissenschaft - manchmal seitens der Zuhörer mit einer gewissen Emphase übersteigert zu einer, Soziologie jenseits von Metaphysik und Werturteilen ' - ein willkommenes ,rationalistisches Gegengift‘ zu gewissen restaurativen Tendenzen der Adenauer-Ära, die ideengeschichtlich als Ausfluß einer ,deutschen Ideologie‘ bildungshumanistischer Provenienz mit idealistisch-geisteswissenschaftlicher Unterlagerung wahrgenommen wurden ... .“

Dabei ist das Verhältnis zu den Schülern nicht immer harmonisch, womit die Soziologie in Köln prinzipiell auch ein weiteres schulentypisches Merkmal aufweist (siehe Tiryakian 1981, S. 43). Auch zwischen den Professoren kriselte es. Ende der 1960er-Jahre kam es zu ,erheblichen Mißstimmungen zwischen Scheuch und König“ (Ute Scheuch 2008, S. 392), die sich dann aufgrund der unterschiedlichen Bewertung der Studierendenproteste 1968 weiter zuspitzten. Die empirische Soziologie wurde immer mehr mit Scheuch, der ihre Institutionalisierung und Professionalisierung auch in der Kölner Soziologielehre wesentlich vorangetrieben hatte, identifiziert; sie geriet nun in den Schulenkämpfen und im Zuge der Politisierung der Studierenden immer mehr in die Defensive und wurde immer weniger als ,,angewandte Aufklärung“ (Dahrendorf 1963) und wissenschaftliche Begleitung des bundesrepublikanischen Demokratisierungsprozesses angesehen, sondern vielmehr als Bewahrerin des status quo. ${ }^{36}$ Auch mit Peter Heintz kam es zum Zerwürfnis. Und Karl-Dieter Opp (2010, S. 82f.) berichtete, wie er Königs Unmut auf sich gezogen habe, aufgrund eines Aufsatzes von Hummell und ihm über „Die Reduzierbarkeit von Soziologie auf Psychologie“, eine Position, die König strikt ablehnte und wegen der Opp schließlich aus dem Schülerkreis ,verbannt“ wurde.

Die Konzentration auf die problem- und empiriezentrierte Ausdifferenzierung der Soziologie führte schließlich dazu, dass zentrale Ausrichtungen Königs auf der Strecke blieben (vgl. Albrecht 2006, S. 583) und er zugunsten seiner politischaufklärerisch und reeducation-Haltung zu einem gewissen Anteil auch gegen seine eigene akademische Herkunft arbeitete. ${ }^{37}$ Die kulturanthropologische Ausrichtung im Ausgang von Thurnwald und den durkheimiens erfuhr (auch in Heintz' Entwick-

\footnotetext{
36 Unter Scheuch wurde die empirische Soziologie „nun zunehmend unpolitisch, defensiv und konservativ. Die Kritik der Protestbewegung wurde in gewisser Weise zu einer sich selbst erfüllenden Prophezeiung“ (Kruse 2006, S. 163).

37 „Im Grunde genommen war Königs Stärke, meine ich immer noch, eine hermeneutische Soziologie im Sinne seiner ursprünglich geplanten Habilitation über die Entstehungs- und Entwicklungsbedingungen der Humboldtschen Universität. Mit seinen breiten Interessen hätte er eigentlich zu Troeltsch, Sombart und Weber gepasst. Aber er war der Meinung, die Deutschen hätten in den Sozialwissenschaften genug Hermeneutik gehabt, sie müssten empirische Sozialforschung betreiben. Daher förderte er Scheuch und andere Leute wie Rüschemeyer, die auf die Empirie setzten und die damals auch die Untersuchung vorantrieben, die zu den berühmten Aufsätzen in der, Kölner Zeitschrift für Soziologie und Sozialpsychologie ' geführt hat über die Selbsteinschätzung der Deutschen. [...] König war sozusagen gespalten zwischen seinen eigentlichen Interessen, wo er dann auch in einer ganz anderen Sprache und mit anderem Temperament heranging, und dem, was er als Wahlsoziologie, Familiensoziologie usw. in Deutschland für notwendig hielt." So der damalige König-Student Hans-Ulrich Wehler (2006, S. 47f.).
} 
lungssoziologie) kaum eine systematische Aufnahme; die soziologische Perspektive der Durkheim-Schule wurde ebenfalls von den Schülern Königs nicht weiter systematisch verfolgt; vielmehr scheinen sich im Laufe der Zeit immer mehr ein an Max Weber orientierter methodologischer Individualismus geschmeidiger mit der Ausrichtung einer amerikanisch geprägten empirischen Sozialforschung in Einklang zu bringen als die französische Durkheim-Schule. ${ }^{38}$ Und was die moralische Gegenwartsdiagnose Königs anging: sie bekam insbesondere in der Person Scheuchs eine konservative Wendung, die dann nach 1968 oftmals die gesamte Wahrnehmung der „Kölner Schule“ als konservative, unkritische oder positivistische Empirieproduzentin leitete und zu Recht zu der von Johanns Weiß (1992) aufgestellten Frage Anlass gab: „Gehört René König zur ,Kölner Schule‘?““

\section{Fazit}

Wenn unter „Kölner Schule“ nur bloße Empirieproduktion und Methodenverfeinerung gefasst wird, dann gehörte König nicht zu dieser Schule. Wenn man aber von einer „Kölner Schule“ im Ausgang von René König und seinen Institutionalisierungsbemühungen sprechen mag, so erscheint uns als deren zentraler Kern eine an gesellschaftlichen Problemen ausgerichtete, empirisch orientierte Ausdifferenzierung und Professionalisierung der bundesrepublikanischen Soziologie - eine Ausrichtung, die sich heute als die vorherrschende normal sociological science durchgesetzt und ,veralltäglicht“" (Tiryakian 1981, S. 42) hat. Heinz Sahner beschrieb das einmal in seinen „Anmerkungen zur ,Kölner Schule““ so, dass die Wirkung Königs und der ,Kölner Schule“ darin liege, ,daß eine theoretisch und empirisch fundierte Soziologie weitgehend zur Selbstverständlichkeit geworden ist“" (Sahner 1992, S. 256). Insofern folgen wir in unserer Charakterisierung oder „Konstruktion“ einer von König ausgehenden „Kölner Schule“ einem Hinweis von Matthias Bös ${ }^{39}$, dass die „Kölner Schule“ sich ,zu Tode gesiegt“ habe, da sie „,das in der amerikanischen Soziologie und in der ISA sich langsam etablierende Bild der Soziologie als eine in unterschiedliche Bindestrichsoziologien aufgeteilte Wissenschaft mit empirisch begründeten Theorien mittlerer Reichweite in den einzelnen Teilgebieten vertrat und somit zum Mainstream wurde." In diesem Sinne kann die in der Einleitung erwähnte Diversität nicht mehr als Gegenargument für das Vorliegen einer „Kölner Schule“ verwendet werden, sondern vielmehr als deren Kern identifiziert werden. Atteslanders oben erwähnter Befund, dass zwar ein übereinstimmendes Vorverständnis von Gesellschaft und den Methoden bestanden habe, spricht zudem viel mehr für als gegen das Vorliegen einer Schule. Auch die Brüche zwischen König und seinen Schülern, die sich in den 1960er-Jahren abzeichneten, sind schulentypisch. Zwar gingen einige Elemente der von König propagierten Soziologie verloren, doch kam es auch zu einer Popularisierung und Veralltäglichung jener Soziologie, die König

\footnotetext{
38 Die geringe Rezeption der durkheimiens durch die Schüler hängt auch mit Königs „,Deutungsmonopol“ hinsichtlich der Durkheim-Schule zusammen, aufgrund dessen kaum jemand der Schüler wagte, sich einzumischen. Für diesen Hinweis danken wir herzlich Heine von Alemann.

39 Persönlicher Hinweis von Matthias Bös vom 18. Oktober 2014.
} 
und dessen Schüler maßgeblich vertreten hatten. In dieser Hinsicht - so können wir resümieren - gibt es kaum einen Aspekt des soziologiegeschichtlichen Schulenbegriffs, der sich nicht in der Geschichte der Soziologie in Köln nachweisen lässt - auch wenn diese „Kölner Schule“ als Schulzusammenhang nur bis zu einem bestimmten Zeitraum bestand (spätestens bis Anfang der 1970er-Jahre).

König ging nicht nach Köln mit der handlungsleitenden Absicht der Bildung einer Schule. Ziel war vielmehr die Konstituierung einer Soziologie, ,die nichts als Soziologie ist, nämlich die wissenschaftlich-systematische Behandlung der allgemeinen Ordnungen des Gesellschaftslebens, ihrer Bewegungs- und Entwicklungsgesetze, ihrer Beziehungen zur natürlichen Umwelt, zur Kultur im Allgemeinen und zu den Einzelgebieten des Lebens und schließlich zur sozial-kulturellen Person des Menschen“ (König 1967, S. 8). Dieses mit empirischer Sozialforschung und mit der Vermittlung internationaler Soziologie unterfütterte Programm richtete er auf unterschiedliche gesellschaftliche Phänomenbereiche aus und baute es durch Lehre, Publikationen und die von ihm geförderten „Schüler“ sukzessive aus, die dann ihrerseits vielfach auf Soziologieprofessuren berufen wurden und diese Art von Soziologie weiter etablierten. Dadurch, dass diese Art von Soziologie sich unmittelbarer, empirischer und ausdifferenzierter an den gesellschaftlichen Problemen abarbeitete als etwa eine kulturpessimistische, die „Totalität" verdinglichender Vergesellschaftung kritisierende Frankfurter Schule, sowie durch die methodische Grundausbildung taten sich die Universitäten mit Berufungen von Kölnern leichter. Das bedeutet nicht, dass die Kölner unkritisch waren, im Gegenteil. König, Scheuch und andere mischten sich durchaus ein und verstanden sich als Aufklärer, aber immer vor dem Hintergrund empirisch gewonnener Einsichten in die gesellschaftliche Realität. Die Kölner, so könnte man pointierter sagen, wirkten mehr in das Fach, während andere Schulen, wie etwa die Frankfurter oder Schelsky (vgl. Moebius 2017a), eher in die Politik oder ins Feuilleton ausstrahlten (vgl. Albrecht et al. 1999). Und so bestimmte die ,erreichte Professionalisierung die konkrete Gestalt der Soziologie auch während der Jahre der neomarxistisch beeinflussten Studentenbewegung an den meisten Universitäten. Der Neomarxismus scheiterte - so kann man sagen - an den Methoden der empirischen Sozialforschung. Der Zwang zur empirischen Konkretion brach auf Dauer Ideologien, wie es Königs Vorstellungen entsprach“ (Lepsius 2006, S. 428).

König förderte die Verbreitung professioneller soziologischer Kriterien und die Ausdifferenzierung, aber er sah sie, wie bereits erwähnt, nie als Selbstzweck, sondern als je nach gesellschaftlicher Problementwicklung notwendigen Spezialisierungsbedarf. Angesichts des sozialen Wandels habe die Soziologie offen zu sein und genau zu prüfen, dass sich die Institutionalisierungen von Spezialdisziplinen nicht verkrusten und ihren Wirklichkeitsbezug verlieren. Auch sah er eine andere Gefahr, der von ihm in Gang gesetzten Prozesse, die Oliver König und Michael Klein folgendermaßen beschreiben: „Daß mit dieser Ausdifferenzierung in Teil-Soziologien die Einheitlichkeit des Faches immer mehr schwand, erfüllte ihn allerdings auch mit Unwohlsein, da er mit dieser Entwicklung nicht in erster Linie eine Verfeinerung und Präzisierung soziologischer Theoriebildung, sondern weit eher einen neuen fachspezifischen Provinzialismus heraufziehen sah. Er wollte verbinden und nicht trennen.“ (Klein und König 1998, S. 12.). Und so erging es ihm und der „Köl- 
ner Schule“" wie in Goethes Zauberlehrling. Die Geister, die er rief, wurde er nicht mehr los. Der Prozess der Teilung war nicht mehr zu stoppen. Er gewann durch den Ausbau des Hochschulwesens und der Soziologie eine solche Eigendynamik, dass die Schule keine Schule mehr blieb und „Köln“ nun überall in der Republik und im anderen deutschsprachigen Raum anzutreffen war. Die Einheitlichkeit des Fachs schwand, damit auch ein klar umrissener Blick auf die Ursprungskonstellation dieser Entwicklung. Vielleicht liegt darin, wie Klein schreibt, auch das Vergessen begründet (vgl. Klein 2014, S. 552), dem der Initiator dieses Prozesses immer mehr anheimfiel.

Funding Open access funding provided by University of Graz.

Open Access Dieser Artikel wird unter der Creative Commons Namensnennung 4.0 International Lizenz (http://creativecommons.org/licenses/by/4.0/deed.de) veröffentlicht, welche die Nutzung, Vervielfältigung, Bearbeitung, Verbreitung und Wiedergabe in jeglichem Medium und Format erlaubt, sofern Sie den/die ursprünglichen Autor(en) und die Quelle ordnungsgemäß nennen, einen Link zur Creative Commons Lizenz beifügen und angeben, ob Änderungen vorgenommen wurden.

\section{Anhang}

Liste der bei René König angefertigten Dissertationen ${ }^{40}$

\section{Philosophische Fakultät an der Universität zu Köln}

- Aich, Prodosh, Farbige unter Weißen, SS 1961, König/[?]

- Albrecht, Günter, Soziologie der geographischen Mobilität, WS 1970/71, König/ Timmermann

- Bigler, Rolf [Rest fehlt]

- Deltgen, Florian, Bewegung als historischer und soziologischer Begriff. Versuch einer theoretischen Präzisierung, SS 1969, Petri/König

- Diemer, Erhard, Abhängigkeit und Selbständlichkeit des Laien im Rahmen der katholischen Kirche im Lichte des II. Vatikanischen Konzils. Zur Religionssoziologie des Laienapostolats, WS 1972/73, König/Engels

- Eckert, Ekkehard-Hédi, Struktur und Funktionen der Familie in Tunesien, untersucht und beschrieben am Beispiel der Grossstadt Tunis, WS 1974/75, König/ Johansen

- Frank, Walter A., Ethnische Grundlagen der Siedlungsstruktur in Mittelnepal, SS 1973, Funke/König

- Freund, Wolfgang Slim, Die Djerbi in Tunesien. Soziologische Analyse einer nordafrikanischen Minderheit, WS 1968/69, König/Petri

- Gerhard, Wilfried, Ernst Troeltsch als Soziologe, SS 1974, König/Landgrebe

\footnotetext{
${ }^{40}$ Die vorliegende Liste wurde 2015 von Michael Klein erstellt und von Oliver König ergänzt. Sie erhebt keinen Anspruch auf Vollständigkeit. Für weitere Hinweise auf Doktoranden und auf Betreuer*innen, die unserer Recherche entglitten sind, wären wir sehr dankbar. Wir danken herzlich Michael Klein und Oliver König für die Überlassung der Liste.
} 
- Hammer, Wolfgang, Untersuchungen zum Erziehungsverständnis von Grund- und Hauptschullehrern, WS 1973/74, König/Menze

- Hammerich, Kurt, Kritische Untersuchungen zur Freizeitpädagogik, 1968, König/ Menze

- Harms, Michael, Gruppenstruktur und ästhetisches Urteil. Ein Beitrag zur empirischen Kunstsoziologie, König/Salber

- Henselder, Helga, Marokko zwischen Demokratie und Diktatur, 1971, Hermens/ König

- Ji Hyun, Whang, Die Entwicklung der Pädagogischen Soziologie in Deutschland, SS 1961, Drechsler/König

- Jurecka, Peter, Soziale und psychologische Integration und Position von Pendlern in ländlichen Gemeinden, SS 1974, König/Anger

- Kamphausen, Hannes, Nativistische, revivalistische, synkretistische und utopische Haltungen in der Dichtung moderner afrikanischer Autoren französischer Sprache, unter besonderer Berücksichtigung Leopold Sedar Senghor's, WS 1968/69, Petri/König

- Klausmeier, Friedrich, Jugend und Musik im technischen Zeitalter: eine repräsentative Befragung in einer westdeutschen Großstadt, SS 1963, König/[?]

- Klein, Michael, Wissenschaftstheoretische Aspekte einer problemorientierten Pädagogik. Ein kritischer Exkurs, WS 1970/71, König/Groothoff

- Korczak, Dieter, Neuere Formen des Zusammenlebens, SS 1979, König/[?]

- Lee, Jong-Ok, Religion und soziale Struktur bei Bergstämmen in Nord-Luzon, SS 1969, Petri/König

- Lehr, Stefan, Der Antisemitismus als religiös bedingtes soziales Vorurteil (18701914), SS 1972, König/Maier

- Lemaire-Pohland, Birgit, zum Problem der Jugenddelinquenz im interkulturellen Vergleich. Soziologische Aspekte der Kriminalforschung und Überlegungen zur Kriminalisierung Jugendlicher in der Bundesrepublik Deutschland und Frankreich, SS. 1974, König/Oehler

- Liesenhoff, Carin, Fontane und das literarische Leben seiner Zeit, WS 1975/76, König/Irmscher

- Lüders, Ameli, Die Vatergestalt im Theaterstück auf der Bühne der Bundesrepublik nach dem 2. Weltkrieg, WS 1971/72, König/Badenhausen

- Mies, Maria, Rollenkonflikte gebildeter indischer Frauen, WS 1971/72, König/ Petri

- Müther, Helga, Schichtspezifische Wertorientierungen von Eltern und ihr Einfluss auf die Intelligenz fünfjähriger Kinder, SS 1974, König/Lehr

- Nutz, Walter, Eine Kulturanalyse von Kei. Beiträge zur vergleichenden Völkerkunde Ostindonesiens, WS 1955/56, Heydrich/König

- Oppitz, Michael, Notwendige Beziehungen - Abriss der strukturalen Anthropologie, SS 1974, König/Johansen

- Singh, Jaspal, Gewerkschaftsführer Indiens, WS 1972/73, König/Petri

- Steininger, Rudolf, Polarisierung und Integration. Eine historisch-kritische Untersuchung des Begriffs der Versäulung in der politischen Soziologie, SS 1974, König/Krebs 
- Starke, Eugen, Das Plato-Bild des George-Kreises, SS 1957, Volckmann-Schluss/ König

- Weidmann, Angelika, Puerto Moral, Monographie eines andalusischen Dorfes, SS 1968, König/Petri

- Weiss, Johannes, Kritische Analyse der Institutionenlehre Arnold Gehlens, WS 1969/70, Landgrebe/König

- Welck, Karin von, Untersuchungen zum sogenannten Konservatismus der PuebloIndianer in Arizona und Neu-Mexiko, SS 1973, Petri/König

- Wilbert, Johannes, Die Fischerei der Indianer im tropischen Urwald von Südamerika, SS 1955, Heydrich/König

\section{Wirtschafts- und Sozialwissenschaftliche Fakultät an der Universität zu Köln}

- Anwar, Mohammad, Bevölkerungs- und Wirtschaftswachstum: Das Wirtschaftswachstum und die Lösung des Bevölkerungsproblems, WS 1970, Wessels/König

- Bals, Christel, Soziologische Probleme in einem Heim der offenen Tür. Eine Einzelfallstudie, SS 1960, König/Heyde

- Baroudi, Firzat M., Die Bedeutung städtischer Agglomerationen im Modernisierungsprozess von Entwicklungsländern - mit besonderer Berücksichtigung der Städte des arabischen Mittleren Ostens, SS 1969, König/Otremba

- Bartscher, Ulrich, Korporationen in Hochschule und Gesellschaft - Eine empirische Studie über traditional orientierte Institutionen in einer nicht wandelnden sozialen Umwelt, SS 1970, König/Scheuch

- Beckers, Hansjoachim, Die kommunale Machtstruktur in einer Pendlergemeinde, SS 1968, König/Scheuch

- Bellebaum, Alfred, Das soziologische System von F. Tönnies unter besonderer Berücksichtigung seiner soziographischen Untersuchungen, WS 1963/64, König/ Weisser

- Benkert, Rolf O., Parado do Bispo - Soziologische Gemeindestudie eines portugiesischen Weinbaudorfes, WS 1960/61, König/Kraus

- Brinkmann, Gerhard, Ausbildung und Arbeitseinkommen, WS 1966/67, Schmölders/König

- Brücher, Otmar, Die soziale Organisation der Leitung eines Industriebetriebes in den Phasen strukturellen Wandels, WS 1969, König/Scheuch

- Brüggen, Gerhard, Soziometrische Strukturen in ausgewählten Klassen wirtschaftsberuflicher Schulen, SS 1964, König/Anger

- Buchner, Dietrich, Kommunikation zwischen Industrie und Medizin durch Hauszeitschriften für Ärzte. Eine werbesoziologische Analyse, WS 1966/67, König/ Scheuch

- Büschges, Günter, Die Gebietsauswahl als Auswahlmethode in der empirischen Sozialforschung - Charakteristika, Grundlagen, Probleme und Bedeutung, WS 1960/61, König/Pfanzagl 
- Büse, Jürgen, Gewerkschaften im Prozess des sozialen Wandels in Entwicklungsländern. Versuch einer historisch-genetischen und strukturell-funktionalen Analyse der Rolle der Gewerkschaften in Ghana, WS 1973, König/Blume

- Busch, Dirk W., Berufliche Wertorientierung und berufliche Mobilität, SS 1972, König/Scheuch

- Buschmann, Elisabeth, Ein soziologischer Bezugsrahmen der Bewährungshilfe, SS 1962, König/Schreiber

- Christiansen, Ursula, Obdachlosigkeit. Gesellschaftliche Reaktionen auf die Armut, SS 1972, Blume/König

- Cisek, Günter, Internationale Personalorganisation, WS 1972/73, König/Meissner

- Cunis, Reinmar, Das Militär in der Demokratie - zur soziologischen Theorie der Wehrverfassung, WS 1963/64, König/Hermens

- Daheim, Hansjürgen, Die Sozialstruktur eines Bürobetriebes. Eine Einzelfallstudie, WS 1957/58, König/Rittershausen

- Dahl, Edgar, Die Unternehmensberatung - Eine Untersuchung ausgewählter Aspekte beratender Tätigkeiten in der BRD, WS 1965/66, König/Gutenberg

- Dennebaum, Eva-Maria, Berufstätigkeit und Lebensphasen verheirateter Frauen, WS 1969/70, König/Savramis

- Diekershoff, Karl-Heinz, Das Wahlverhalten von Mitgliedern organisierter Interessensgruppen. Dargestellt am Beispiel der Bundestagswahlen 1961, WS 1964/65, König/Hermens

- Drewe, Paul, Der Beitrag der Sozialforschung zur Regional- und Stadtplanung Entwurf eines soziologischen Forschungsprogramms und erste Erfahrungen mit einer soziologischen Beratung, WS 1966/67, Scheuch/König

- Ellinghaus, Dieter, Aufbau und Konsistenz von Wertsystemen - Eine Untersuchung von Wertvorstellungen bei Handwerkern, WS 1969/70, König/Schmölders

- Esser, Hartmut, Soziale Regelmässigkeiten des Befragtenverhaltens, WS 1973/74, König/Mayntz

- Esters, Ernst August, Soziale Beeinflussung - Eine sozialpsychologische Theorie, WS 1960/61, König/Albert

- Esteve, Esteban Hernández, Die Arbeit und die Azteken, SS 1964, Kellenbenz/ König

- Farhang, Amin, Die sozio-ökonomischen Aspekte der Entwicklungsplanung, dargestellt am Beispiel Afghanistans, SS 1974, König/Rettig

- Fischer, Mechtild, Der Mittelklassenbegriff als normative Kategorie des politischen und sozialen Selbstverständnisses in Frankreich seit 1791, WS 1971/72, König/Schmölders

- Fischer, Winfried M., Die Sozialstruktur industrieähnlicher Betriebe, WS 1959/60, König/Heyde

- Frantzen, Rainer, Der Ablauf des Wirtschaftsjahres im städtisch-industriellen Bereich, dargestellt am Beispiel der Stadt Köln, SS 1974, Otremba/König

- Frey, Hans Ludwig, Soziale Prozesse in Untergrundbewegungen, SS 1952, von Wiese/König

- Fröhlich, Dieter, Nationalismus und Nationalstaat in Entwicklungsländern. Probleme der Integration ethnischer Gruppen in Afghanistan, WS 1968/69, König/ Kellenbenz 
- Fröhlich, Karl-Heinz, Die sozialen Schichtungen und Umschichtungen in Deutschland in der Zeit der Hochindustrialisierung, SS 1959, Specht/König

- Fügel, Lothar, Die Bedeutung der philosophischen Anthropologie für die Grundlegung der Sozialwissenschaften, SS 1967, Müller-Armack/König

- Gores, Peter, Die sozialen Verhaltensweisen alter Menschen. Versuch einer Systematisierung, WS 1970/71, König/Blume

- Greber, Josef, Das Schuhmacherhandwerk in den fortgeschrittenen Industriegesellschaften, SS 1963, König/Schreiber

- Gugler, Josef, Die neuere französische Soziologie, SS 1959, König/Heintz

- Haack, Renate, Berufswunsch und Berufswahl in Familie in soziologischer Sicht. Eine Untersuchung anhand von Schülerkarten von 13.300, SS 1956, König/Heyde

- Habermann, Inge, Kirchgänger-Image und Kirchgangsfrequenzen, WS 1965/66, König/Anger

- Hagemann, Friedhelm, Zur sozialen Lage im selbständigen Lebensmittel-Einzelhandel, SS 1960, König/Rittershausen

- Heim, Joachim, Programmierer und Systemanalytiker. Berufssoziologische Aspekte, SS 1974, König/Grochla

- Helmer, Hans-Josef, Religion und Wirtschaft - die neuere Kritik der Weber-These, WS 1970/71, König/Neumann

- Hentschel, Rüdiger, Der Redakteur als Schlüsselfigur im Kommunikationsprozess der Zeitung, SS 1964, König/Scheuch

- Herz, Thomas, Soziale Bedingungen für Rechtsextremismus in der Bundesrepublik und in den Vereinigten Staaten, SS 1973, Scheuch/König

- Hesse-Quack, Otto, Soziale Implikationen interkultureller Übertragungsprozesse (dargestellt am Phänomen der Veränderung von Filmen durch Synchronisation), WS 1966/67, König/Silbermann

- Hitschmann, Peter, Der Einfluss der Gruppenzugehörigkeit auf die Konsumgewohnheiten, WS 1958/59, König/Schmölders

- Hondrich, Karl Otto, Die Ideologie von Interessenverbänden. Eine strukturellfunktionale Analyse öffentlicher Äusserungen des Bundesverbandes Deutscher Industrie, der Bundesvereinigung Deutscher Arbeitgeberverbände und des Deutschen Gewerkschaftsbundes, SS 1962, König/Weisser

- Hugelhofer, Hansjakob, Die Institutionalisierung des Gewerkschaftsprinzips als soziologischer Prozess, aufgewiesen an der Entwicklung der englischen Trade Unions zwischen 1850 und 1875, SS 1955, König/Beutin

- Hummell, Hans-Joachim, Psychologische Ansätze einer Theorie sozialen Verhaltens, SS 1969, König/Scheuch

- Hussmann, Horst, Studien zur Entstehungsgeschichte der deutschen Betriebssoziologie. Das Problem der informellen Gruppe in der älteren deutschen Betriebssoziologie, WS 1957/58, König/Heintz

- Janowsky, Bernd, Das Problem der sozialen Organisation, WS 1969/70, Grochla/ König

- Joswig, Rosemarie, Bedürfnis und Qualität. Ein Beitrag zur Interpretation des Qualitätsbegriffs, WS 1970/71, Kutzelnigg/König

- Kamp, Ferdinand, Der Wandel von Berufsrolle und Status des Volksschullehrers, SS 1964, König/Schreiber 
- Karboul, Mohammed, Politische und sozial-ökonomische Probleme der Integration der Meghreb, WS 1970/71, Müller-Armack/König

- Kaupen-Haas, Heidrun, Stabilität und Wandel ärztlicher Autorität. Eine Anwendung soziologischer Theorie auf Aspekte der Arzt-Patient-Beziehung, SS 1968, König/Scheuch

- Kersig, Hans-Jürgen, Die nivellierte Mittelstandsgesellschaft, WS 1960/61, König/Hermens

- Kliemt, Gundolf, Die Praxis der Mitbestimmung im Dienstleistungssektor aus der Sicht der Betriebsratvorsitzenden, SS 1969, Blume/König

- Klingemann, Hans Dieter, Bestimmungsgründe der Wahlentscheidung im Bundeswahlkreis Heilbronn. Eine regionale Wahlanalyse, WS 1966/67, Scheuch/ König

- Kodjo, Samuel, Bildungsplanung in Afrika südlich der Sahara, unter besonderer Berücksichtigung des Universitätsunterrichts in den Wirtschafts- und Sozialwissenschaften, SS 1968, König/Schölders

- Künzel, Renate, Der Werbefachmann. Eine empirische Studie zur Entstehung neuer Berufspositionen, SS 1969, König/Scheuch

- Küster, Horst E., Zur Analyse der soziologisch relevanten Ursachen des Krankenstandes, SS 1968, König/Schreiber

- Kuhlmann, Marlies, Der Weg der Wirtschaftsnachricht und ihre Stellung im Wirtschaftsteil der Tageszeitung, SS 1957, König/Heyde

- Kunczik, Michael, Gewaltdarstellungen in den Unterhaltungssendungen des Fernsehens. Eine Diskussion der zur Analyse potentiell kriminogener Effekte von Gewaltdarstellungen im Fernsehen vorliegenden theoretischen Konzepte und Forschungsergebnisse unter besonderer Berücksichtigung kriminalsoziologischer Aspekte, WS 1974/75, König/Silbermann

- Kunz, Gerhard, Probleme der Anwendung von Soziologie und Sozialforschung. Eine Analyse der Beziehungen zwischen wissenschaftlichem Aussagesystem und sozialpraktischen Entscheidungen, dargestellt an einer empirischen Untersuchung aus dem Bereich der Hochschulplanung, SS 1968, König/Scheuch

- Lippold, Klaus W., Ansatzpunkte zur systemorientierten Betrachtung des Verbandes. Analyse der Deutschen Kolpingfamilie. Ein Beitrag zur Verbandstheorie, WS 1971/72, Schreiber/König

- Luthe, Karl Otto, Die Bedeutung wechselseitiger Kommunikation im Prozess der Beeinflussung. Beitrag zu einer soziologischen Theorie der Kommunikation, SS 1966, König/Silbermann

- Markefka, Manfred, Der Begriff der Jugend in der deutschen Nachkriegsliteratur zum Problem der Jugend, SS 1963, König/Albert

- Mauntel, Jobst Friedrich, Der Verrat und seine Einflüsse auf das gesellschaftliche Leben, SS 1954, von Wiese/König

- Moeller, Carola, Die Einführung der ungelernten Jungarbeiter in den industriellen Arbeitsprozess. Eine Situationsanalyse, WS 1964/65, König/Scheuch

- Mogs, Fritz, Die sozialgeschichtliche Entwicklung der Stadt Oberhausen/Rhld. zwischen 1850 und 1933, WS 1956/57, Beutin/König 
- Moll, Maren, Die Teilzeitarbeit. Ein Lösungsversuch der Schwierigkeiten der ausserhäuslich erwerbstätigen Frau mit Kindern. Forschungen und Probleme, WS 1959/60, Specht/König

- Müller-Neuhof, Klaus, Kommunikationspolitik und Kommunikationsprognose. Ein Beitrag zum Entwurf einer soziologisch ausgerichteten Theorie der Kommunikationspolitik, SS 1974, Silbermann/König

- Nave-Herz, Rosemarie, Die Elternschule. Entwicklung und Stand der institutionalisierten Elternerziehung in Westdeutschland und West Berlin, WS 1962/63, König/Schreiber

- Nemetzade, Kamal, Strukturanalyse des sozialen Konfliktes, SS 1974, König/ Savramis

- Nettekoven, Lothar, Massentourismus in Tunesien. Soziologische Untersuchungen an Touristen aus hochindustrialisierten Gesellschaften, WS 1970/71, König/ Scheuch

- Nürnberg, Norbert, Spannungen und Konflikte in den zwischenmenschlichen Beziehungen von Angestelltengruppen - zwei Einzelfallstudien, SS 1969, König/ Blume

- Ologoudou, Emile, Quellen und Bedeutung des afrikanischen Sozialismus, WS 1965/66, König/Scheuch

- Opp, Hans Dieter, Zur Erklärung delinquenten Verhaltens von Kindern und Jugendlichen. Eine ökologische Analyse der Kinder- und Jugenddelinquenz in Köln und eine Kritik des kriminalökologischen Ansatzes, SS 1967, König/Scheuch

- Osafo, Ernest A., Der Beitrag der Basler Mission zur wirtschaftlichen Entwicklung Ghanas von 1828 bis zum Ersten Weltkrieg, SS 1972, König/Müller-Armack

- Panse, Winfried, Industriesoziologie in Schweden, WS 1966/67, König/[?]

- Pintar, Rüdiger, Beruf und Ideologie. Vermittlung und Konsequenzen beruflicher Orientierungen bei Arbeitern, SS 1974, König/Mayntz

- Philipp, Guntram, Die Wirksamkeit der Herrenhuter Brüdergemeinde unter den Esten und Letten z.Zt. der Bauernbefreiung, WS 1967/68, König/Kellenbenz

- Ralis, Max, Über einige Erfahrungen aus der Praxis der Sozialforschung - Kommunikationsverhalten, SS 1953, König/Heyde

- Renn, Heinz, Methodologische Probleme der quantitativen Bestimmung rollenkongruenter Sozialisierungswirkungen, SS 1973, König/Ziegler

- Reschka, Willibald, Hochschule und Gesellschaft. Eine Untersuchung zur Entwicklung des Hochschulwesens in Polen, WS 1974/75, König/Scheuch

- Riemann, Christa, Der Kommunikationsfluss von einer Gewerkschaftsleitung zu ihren Funktionären über das Medium einer Zeitschrift und die Aufnahme des Kommunikationsinhaltes durch die Funktionäre, SS 1964, König/Weisser

- Rinas, Otto, Untersuchungen über die sozialpsychologischen Hintergründe der Werbung, WS 1954/55, König/Seyffert

- Rink, Jürgen, Zeitung und Gemeinde, SS 1963, König/Anger

- Ritz, Hans-Otto, Die Bildungsinteressen der sozialen Schichten. Eine Untersuchung der Hörerschaft der Volkshochschule Wuppertal, unter besonderer Berücksichtigung der Arbeiter- und Angestelltenschaft, WS 1956/57, Specht/König

- Roghmann, Klaus, Beiträge zur Erforschung von Dogmatismus und Autoritarismus, WS 1964/65, König/Scheuch 
- Rohe, Hans-Dieter, Differentielle Anzeigenwirkung bei einzelnen sozialen Schichten, WS 1970/71, Anger/König

- Rosner, Alois, Beiträge zur Soziologie der Freizeit, SS 1974, König/Scheuch

- Rüschemeyer, Dietrich, Probleme der Wissenssoziologie. Eine Kritik der Arbeiten Karl Mannheims und M. Schelers und eine Erweiterung der wissenssoziologischen Fragestellung am Beispiel der Kleingruppenforschung, WS 1957/58, König/ Weisser

- Rüther, Werner, Die Stellung des Labeling Approach im Rahmen der Theorie abweichenden Verhaltens, SS 1974, König/Kaufmann (jur. Fakultät)

- Saarbourg, Erich-Alexander, Frustration und Autoritarismus, WS 1958/59, Heintz/ König

- Sack, Fritz, Probleme der Integration und Anpassung im Handwerk, SS 1963, König/Albert

- Sahner, Heinz, Forschungsgruppen und technischer Fortschritt, SS 1973, Scheuch/ König

- Samii, Said, Wandlungen in der Sozialstruktur der Bevölkerung Afghanistans im Entwicklungsprozess 1950 bis zur Gegenwart, SS 1974, Otremba/König

- Sawitzki, Hans-Henning, Die Elitegruppe der Akademiker in einem Entwicklungsland, dargestellt am Beispiel Afghanistans, WS 1969/70, König/Blume

- Savramis, Demosthenes, Zur Soziologie des byzantinischen Mönchtums, SS 1960, König/Rubin

- Sieben, Manfred, Die Prüfung der Validität von Untersuchungsmethoden zur Analyse deutscher Genossenschaften, SS 1965, König/Weisser

- Sigurjonsson, Jon Saemundur, Sozialpolitik im Weltmassstab. Versuch einer Darstellung am Beispiel des UN/FAO-Welternährungsprogramms, WS 1974/75, Schreiber/König

- Sodeur, Wolfgang, Wirkungen des Führungsverhaltens in kleinen Formalgruppen, SS 1970, König/Scheuch

- Scheele, Walter, Quoten-Sampling. Grundprobleme und Ergebnisse einer Parallelerhebung in der Stadt Köln, WS 1955/56, König/Heyde

- Scheidewind, Dieter, Beobachtungen über den Widerstand bei Arbeitsplatzwechsel, SS 1962, König/Anger

- Scheuch, Erwin K., Auswahlverfahren in der Sozialforschung. Ihre Anwendung bei Repräsentativ-Befragungen, SS 1956, König/Breuer

- Schiefer, Friedrich, Elektronik und Angestellte. Das Eindringen der elektronischen Datenverarbeitung in die Büroarbeit mit seinen Auswirkungen auf die Orientierung der Angestellten und die soziale Organisation des Bürobetriebes, SS 1968, König/Grochla

- Schmelzer, Horst, Kommunikation und Gesellschaft. Wertvorstellungen über Naturwissenschaft und Technik in der deutschen Presse, SS 1967, König/Silbermann

- Schneider, Annerose, Expressive Verkehrskreise. Eine empirische Untersuchung zu freundschaftlichen und verwandtschaftlichen Beziehungen, SS 1969, Scheuch/ König

- Schneider, Norbert, Parteien und Kandidaten. Die Bundestagswahl 1969 im Wahlkreis 135 (Obertaunuskreis), SS 1972, Hermens/König 
- Schöber, Peter, Die Wirtschaftsmentalität der westdeutschen Handwerker, SS 1967, König/[?]

- Schuckmann, Gunnar von, Die politische Willensbildung in der Grossstadt Köln seit der Reichsgründung im Jahre 1871, WS 1965/66, König/Hermens

- Spangenberg, Werner, Die Haltung des Menschen zum betriebswirtschaftlichen Fortschritt seit 1945, WS 1954/55, Beste/König

- Speckmann, Rolf, Der ungelernte Arbeiter in der Industrie. Ein soziologischer und sozialpsychologischer Beitrag, WS 1958/59, Specht/König

- Stehmanns, Heinrich, Möglichkeiten der Steuerung des Krankenstandes durch Einzelsoziotherapie in der gesetzlichen Krankenversicherung, SS 1967, Schreiber/ König

- Steinkamp, Günter, Eine Analyse der die vertikale Intergenerationen-Berufsmobilität in industriellen Gesellschaften verursachenden und beeinflussenden Faktoren, WS 1961/62, König/Schreiber

- Stendenbach, Franz-Josef, Soziale Interaktion und Lernprozesse, SS 1961, König/ Albert

- Steglitz, Heinz, Der gesellschaftliche Auftrag der freien Berufe. Eine soziologische Analyse der spezifisch freiberuflichen Tätigkeit innerhalb der Funktionen der Kulturberufe, SS 1959, König/Heyde

- Stumme, Wolfgang, Die differenzierten Vorstellungen des Laien zum Problemkreis psychischer Erkrankungen. Eine Kritik der Vorurteilsforschung, SS 1973, König/Bergler

- Swertz, Paul, Rollenanalyse im Krankenhaus, SS 1968, Scheuch/König

- Temme, Mathilde, Wirtschaft und Bevölkerung in Südecuador, SS 1972, Otremba/ König

- Teuber, Horst, Führungsgrundlagen in einer Einkaufsgenossenschaft, WS 1969/70, König/Scheuch

- Uhen, Leo, Gruppenbewusstsein und informelle Gruppenbildung bei deutschen Arbeitern im Jahrhundert der Industrialisierung, WS 1962/63, König/Rittershausen

- Urbat, Frank, Der Wechsel in die unternehmerische Selbständigkeit, SS 1973, König/Scheuch

- Volks, Holger, Anwaltliche Berufsrollen und anwaltliche Berufsarbeit in der Industriegesellschaft, SS 1974, König/Mayntz

- Wald, Renate, Junge Arbeiterinnen. Eine Schilderung ihrer sozialen Situation, SS 1959, König/[?]

- Wegner, Kurt, Der Tanzlehrer. Strukturanalyse eines Berufes als Beitrag zur Soziologie des Tanzens, WS 1961/62, König/Kellenbenz

- Weidmann, Alfred Rudolf, Grundlagen einer Kommunikationssoziologie, SS 1970, König/Ungeheuer (Bonn)

- Welmer, Hans-Josef, Religion und Wirtschaft. Die neuere Kritik der Weberthese, WS 1970/71, Neumann/König

- Welter, Karl, Eine Beurteilung des REFA-Systems vom Standpunkt des Soziologen, SS 1962, König/Beste

- Werlhof, Claudia von, Der Prozess der Unterentwicklung und die Reaktionen der Unterentwickelten in Zentralamerika (Eine vergleichende Studie über El Salvador und Costa Rica), SS 1974, König/Lühr (Berlin) 
- Wernerus, Theodor, Die Massenkommunikationsmittel und der Bundestageswahlkampf 1961, WS 1965/66, König/Silbermann

- Willenborg, Gertrud, Von deutschen Helden. Eine Inhaltsanalyse der Karl-MayRomane, WS 1966/67, König/Silbermann

- Ziegler, Rolf, Kommunikationsstruktur und Leistung sozialer Systeme, WS 1966/67, König/Scheuch

\section{Literatur}

Albrecht, Clemens. 2002. Literaturbesprechung. Kölner Zeitschrift für Soziologie und Sozialpsychologie 54:163-166.

Albrecht, Clemens. 2006. Die Wendung ins Subjekt. Gesellschaftsanalyse und Psychotherapie. In Der Gestaltungsanspruch der Wissenschaft. Aufbruch und Ernüchterung in den Rechts-, Sozial- und Wirtschaftswissenschaften auf dem Weg von den 1960er zu den 1980er Jahren, Hrsg. Karl Acham, Knut Wolfgang Nörr und Dian Schefold, 577-591. Stuttgart: Franz Steiner.

Albrecht, Clemens. 2013. Nachwort. In Emile Durkheim. Zur Bestimmung der französischen Soziologie in Deutschland. Schriften Bd. 8, René König, 387-413. Wiesbaden: Springer VS.

Albrecht, Clemens, Günter C. Behrmann, Michael Bock und Harald Homann. 1999. Die intellektuelle Gründung der Bundesrepublik. Eine Wirkungsgeschichte der Frankfurter Schule. Frankfurt a. M.: Campus.

Alemann, Heine von. 1981. Leopold von Wiese und das Forschungsinstitut für Sozialwissenschaften in Köln 1919 bis 1934. In Geschichte der Soziologie, Bd. 2, Hrsg. Wolf Lepenies, 349-389. Frankfurt a. M.: Suhrkamp.

Alemann, Heine von. 1999. Köln. Die Tradition der Fakultät für Wirtschafts- und Sozialwissenschaften. Soziologie. Mitteilungsblatt der Deutschen Gesellschaft für Soziologie 2:81-87.

Alemann, Heine von. 2000. Nachwort. In René König, Zur Konstitution moderner Gesellschaften. Studien zur Frühgeschichte der Soziologie. Schriften. Bd. 7, hrsg. und mit einem Nachwort versehen von Heine von Alemann, 315-336. Opladen: Leske + Budrich.

Alemann, Heine von, und Gerhard Kunz. Hrsg. 1992. René König. Gesamtverzeichnis der Schriften. In der Spiegelung von Freunden, Schülern, Kollegen. Opladen: Westdeutscher Verlag.

Atteslander, Peter. 1992. Einer, der von außen kommt. Festvortrag zum 85. Geburtstag von René König. In René König. Gesamtverzeichnis der Schriften, Hrsg. Heine von Alemann und Gerhard Kunz, 170-180. Opladen: Westdeutscher Verlag.

Atteslander, Peter. 1996. Bruchstïcke. In Wege zur Soziologie nach 1945. Biographische Notizen, Hrsg. Christian Fleck, 161-183. Opladen: Leske + Budrich.

Atteslander, Peter. 1998. Soziologische Orientierung - Verantwortung und Ohnmacht der Sozialwissenschaft. In Soziologie als Beruf. Erinnerungen westdeutscher Hochschulprofessoren der Nachkriegsgeneration. Soziale Welt. Sonderband 11, Hrsg. Karl Martin Bolte und Friedhelm Neidhardt, 131-149. Baden-Baden: Nomos.

Atteslander, Peter. 2008. Nachwort mit Würdigung der Lebensleistung Erwin K. Scheuchs. In Erwin K. Scheuch - Eine Biographie. Band I. Es mußte nicht Soziologie sein, aber es war besser so. Mit einem Nachwort von Peter Atteslander und Ute Scheuch, 419-429. Bad Schussenried: Hess Verlag.

Becher, Tony. 1989. Academic tribes and territories: Intellectual enquiry and the cultures of disciplines. Milton Keynes (UK): Open University Press.

Becher, Tony, und Paul Trowler. 2001. Academic tribes and territories: Intellectual enquiry and the culture of disciplines. Second Edition. Buckingham, Philadelphia (PA): Open University Press.

Benninghaus, Hans, und Nico Stehr. 1992. Erkenntnis und Offenheit. In René König. Gesamtverzeichnis der Schriften, Hrsg. Heine von Alemann und Gerhard Kunz, 195-199. Opladen: Westdeutscher Verlag.

Bourdieu, Pierre, Jean-Claude Chamboredon und Jean-Claude Passeron. 1991. Soziologie als Beruf. Wissenschaftstheoretische Voraussetzungen soziologischer Erkenntnis. Berlin: de Gruyter.

Büschges, Günter. 1992. Empirische Soziologie in praktischer Absicht. In René König. Gesamtverzeichnis der Schriften, Hrsg. Heine von Alemann und Gerhard Kunz, 200-205. Opladen: Westdeutscher Verlag. 
Crane, Diana. 1972. Invisible colleges: Diffusion of knowledge in scientific communities. Chicago: The University of Chicago Press.

Daheim, Hansjürgen. 1998. Soziologie als Beruf in der Universität - autobiographische Notizen. In Soziologie als Beruf. Erinnerungen westdeutscher Hochschulprofessoren der Nachkriegsgeneration. Sonderband 11 der Sozialen Welt, Hrsg. Martin Bolte und Friedhelm Neidhardt, 315-329. Baden-Baden: Nomos.

Dahrendorf, Ralf. 1960. Die drei Soziologien. Zu Helmut Schelskys „Ortsbestimmung der deutschen Soziologie“. Kölner Zeitschrift für Soziologie und Sozialpsychologie 12:120-133.

Dahrendorf, Ralf. 1963. Die angewandte Aufklärung. Gesellschaft und Soziologie in Amerika. München: Piper.

Dayé, Christian. 2016. Schools in the social and behavorial sciences: Concepts and historical relevance. In International Encyclopedia of Social \& Behavorial Science (2nd Edition), Hrsg. James D. Wright, 128-133. Oxford: Elsevier.

Dayé, Christian. 2017. Soziologische Konzeptionalisierungen von wissenschaftlichen Kollektiven und ihr Einsatz in der Soziologiegeschichte. In Geschichte der deutschsprachigen Soziologie, Bd. 2: Forschungsdesign, Theorien und Methoden, Hrsg. Stephan Moebius und Andrea Ploder, 63-80. Wiesbaden: Springer VS.

Dreier, Volker. 2017. Geschichte der Kölner Zeitschrift für Soziologie und Sozialpsychologie. In Geschichte der deutschsprachigen Soziologie, Bd. 1: Geschichte der Soziologie im deutschsprachigen Raum, Hrsg. Stephan Moebius und Andrea Ploder, 921-935. Wiesbaden: Springer VS.

Dreier, Volker. (i. E.) Konturen der Kölner Zeitschrift für Soziologie und Sozialpsychologie. Zu Konstellationen und Resonanzen einer soziologischen Fachzeitschrift im Zeitverlauf 1921-2019. Kölner Zeitschrift für Soziologie und Sozialpsychologie 72

Farrell, Michael P. 2001. Collaborative circles: Friendship dynamics \& creative work. Chicago: The University of Chicago Press.

Fischer, Joachim, und Stephan Moebius. Hrsg. 2019. Soziologische Denkschulen. Zur Archäologie der bundesrepublikanischen Soziologie. Wiesbaden: Springer VS.

Gorges, Irmela. 1986. Sozialforschung in der Weimarer Republik 1918-1933. Frankfurt a. M.: Hain Verlag.

Hoffmann-Nowotny, Hans-Joachim. 1992. René König - aus Zürich. In René König. Gesamtverzeichnis der Schriften, Hrsg. Heine von Alemann und Gerhard Kunz, 218-221. Opladen: Westdeutscher Verlag.

Hummell, Hans-Joachim. 1998. Nachwort. In René König. Kritik der historisch-existenzialistischen Soziologie. Ein Beitrag zur Begründung einer objektiven Soziologie, Schriften Bd. 3, neu hrsg. und mit einem Nachwort versehen von Hans-Joachim Hummell, 309-323. Opladen: Leske + Budrich.

Kaesler, Dirk. 1997. Die Gründung des Forschungsinstituts für Soziologie der Universität zu Köln und die zwanziger Jahre. In Soziologie als Berufung. Bausteine einer selbstbewussten Soziologie, Dirk Kaesler, 235-247. Opladen: Westdeutscher Verlag.

Klausnitzer, Ralf. 2014. Denkkollektiv oder Klüngelsystem? Wissenschaftliche Schulen im Spannungsfeld von Selbst- und Fremdbeobachtungen. INDES. Zeitschrift für Politik und Gesellschaft 3:8-19.

Klein, Michael. 2006. Nachwort. In René König, Strukturanalyse der Gegenwart. Schriften. Bd. 12, hrsg. und mit einem Nachwort versehen von Michael Klein, 377-412. Wiesbaden: VS Verlag für Sozialwissenschaften.

Klein, Michael. 2014. Nachwort. In René König, Aufgaben des Soziologen und die Perspektiven der Soziologie. Schriften zur Entwicklung der Soziologie nach 1945, Schriften Bd. 10, hrsg. und mit einem Nachwort von Michael Klein, 551-581. Wiesbaden: Springer VS.

Klein, Michael, und Oliver König. 1998. Einführung. In René König, Soziologe und Humanist. Texte aus vier Jahrzehnten, Hrsg. Michael Klein und Oliver König, 9-15. Opladen: Leske + Budrich.

Klingemann, Carsten. 1988. Kölner Soziologie während des Nationalsozialismus. In Nachhilfe zur Erinnerung. 600 Jahre Universität zu Köln, Hrsg. Wolfgang Blaschke, Olaf Hensel, Peter Liebermann, Wolfgang Lindweiler sowie der Redaktion der Uni-Stadt-Revue Köln, 76-97. Köln: Pahl-Rugenstein.

Knebelspieß, Stefanie, und Stephan Moebius. 2019. Programm, personelle und organisatorische Entwicklung des Forschungsinstituts für Sozialwissenschaften von 1918/19 bis zum heutigen Institut für Soziologie und Sozialpsychologie (ISS). Kölner Zeitschrift für Soziologie und Sozialpsychologie 71.

König, Jan-Hendrik. 2014. Wissenssoziologische Suchbewegungen. Die Funktion von Schulen für die Wissenschaft. INDES. Zeitschrift für Politik und Gesellschaft 3:20-27.

König, René. 1949. Soziologie heute. Zürich: Regio.

König, René. Hrsg. 1967. Soziologie. Fischer-Lexikon, umgearbeitete und erw. Neuausgabe. Frankfurt a. M.: Fischer. 
König, René. 1973. Soziologische Orientierungen. Vorträge und Aufsätze. Köln: Kiepenheuer \& Witsch.

König, René. 1976. Vorwort des Herausgebers zur zweiten Auflage. In Handbuch der empirischen Sozialforschung. Band 5: Soziale Schichtung und Mobilität, Hrsg. René König, VII-XIV. Stuttgart: Enke/DTV.

König, René. 1978. Émile Durkheim zur Diskussion. Jenseits von Dogmatismus und Skepsis. München: Hanser.

König, René. 1979. Einige Bemerkungen über die Bedeutung der empirischen Forschung für die Soziologie. In Handbuch der empirischen Sozialforschung. Band 14: Religion - Bildung - Medizin, Hrsg. René König, 345-375. Stuttgart: Enke/DTV.

König, René. 1984. Leben im Widerspruch. Versuch einer intellektuellen Autobiographie. Frankfurt a. M.: Ullstein.

König, René. 1987. Soziologie in Deutschland. Begründer/Verfechter/Verächter. München, Wien: Hanser.

König, René. 1988. „Tout va très bien ...“ René König über Emigration und Nachkriegssoziologie im Gespräch mit Wolf Schönleiter. In Nachhilfe zur Erinnerung. 600 Jahre Universität zu Köln, Hrsg. Wolfgang Blaschke, Olaf Hensel, Peter Liebermann, Wolfgang Lindweiler sowie der Redaktion der Uni-Stadt-Revue Köln,139-158. Köln: Pahl-Rugenstein.

König, René. 1989. Identität und Anpassung im Exil. In Kultur und Gesellschaft. Verhandlungen des 24. Deutschen Soziologentags, des 11. Österreichischen Soziologentags und des 8. Kongresses der Schweizerischen Gesellschaft für Soziologie in Zürich 1988, Hrsg. Max Haller, Hans-Joachim Hoffmann-Nowotny und Wolfgang Zapf, 113-126. Frankfurt a. M.: Campus.

König, René. (1998a). Einige Bemerkungen über die Bedeutung der empirischen Sozialforschung in der Soziologie. In René König, Soziologe und Humanist. Texte aus vier Jahrzehnten, Hrsg. Michael Klein und Oliver König, 140-148. Opladen: Leske + Budrich.

König, René. (1998b). Vorbemerkung des Herausgebers zum Jahrgang VII der Kölner Zeitschrift für Soziologie und Sozialpsychologie. In René König, Soziologe und Humanist. Texte aus vier Jahrzehnten, Hrsg. Michael Klein und Oliver König, 103-107. Opladen: Leske + Budrich.

König, René. 2000. Briefwechsel, Bd. 1. Schriften, Bd. 19, Hrsg. Mario und Oliver König und mit einem Nachwort versehen von Oliver König. Opladen: Leske + Budrich.

König, René. (i. E.) Zürcher Vorlesungen, Hrsg. Stephan Moebius und Martin Griesbacher. Berlin: Suhrkamp.

Kraushaar, Wolfgang. Hrsg. 1998. Frankfurter Schule und Studentenbewegung. Von der Flaschenpost zum Molotowcocktail 1946-1995, 3 Bde. Frankfurt a. M.: Rogner \& Bernhard.

Krekel-Eiben, Elisabeth M. 1990. Soziologische Wissenschaftsgemeinschaften. Ein struktureller Vergleich am Beispiel der Fachpublikationen in der Bundesrepublik Deutschland und den USA. Wiesbaden: DUV.

Kruse, Volker. 2006. Soziologie als „Schlüsselwissenschaft“ und „Angewandte Aufklärung“ - der Mythos der Empirischen Soziologie. In Der Gestaltungsanspruch der Wissenschaft. Aufbruch und Ernüchterung in den Rechts-, Sozial- und Wirtschaftswissenschaften auf dem Weg von den 1960er zu den 1980er Jahren, Hrsg. Karl Acham, Knut W. Nörr und Bertram Schefold, 145-175. Stuttgart: Franz Steiner.

Kuhn, Thomas S. 1973. Die Struktur wissenschaftlicher Revolutionen. Frankfurt a. M.: Suhrkamp.

Lepsius, M. Rainer. 1979. Die Entwicklung der Soziologie nach dem Zweiten Weltkrieg. 1945-1967. In Kölner Zeitschrift für Soziologie und Sozialpsychologie, Sonderheft 21, Hrsg. Günther Lüschen, 25-70. Opladen: Westdeutscher Verlag.

Lepsius, M. Rainer. 1992. Frische Luft durch geöffnete Fenster. René König 1951 und später. In René König. Gesamtverzeichnis der Schriften, Hrsg. Heine von Alemann und Gerhard Kunz, 238-241. Opladen: Westdeutscher Verlag.

Lepsius, M. Rainer. 2006. René Königs Beitrag zur Soziologie in Deutschland. Kölner Zeitschrift für Soziologie und Sozialpsychologie 58:425-432.

Lepsius, M. Rainer. 2017. Neubegründung. 1978. In Soziologie und Soziologen. Aufsätze zur Institutionalisierung der Soziologie in Deutschland, Hrsg. M. Rainer Lepsius, 79-84. Tübingen: Mohr Siebeck.

Lüschen, Günther. 1979. Die Entwicklung der deutschen Soziologie in ihrem Fachschrifttum. Perioden, Sachgebiete und Methode seit 1945. In Kölner Zeitschrift für Soziologie und Sozialpsychologie, Sonderheft 21, Hrsg. Günther Lüschen, 169-192. Opladen: Westdeutscher Verlag.

Lüschen, Günther. 1992. René Königs Altruismus. In René König. Gesamtverzeichnis der Schriften, Hrsg. Heine von Alemann und Gerhard Kunz, 242-246. Opladen: Westdeutscher Verlag.

Lüschen, Günther. 1995. 25 Jahre deutscher Nachkriegssoziologie - Institutionalisierung und Theorie. In Soziologie in Deutschland. Entwicklung, Institutionalisierung und Berufsfelder. Theoretische Kontroversen, Hrsg. Bernhard Schäfers, 11-33. Opladen: Springer. 
Lutz, Burkart. 2000. Soziologie als Entdeckung. In Soziologie als angewandte Aufklärung. Weniger als erwartet, aber mehr als zu befürchten war. Die Entwicklung der Nachkriegssoziologie aus der Sicht der frühen Fachvertreter, Hrsg. Heinz Sahner, 35-43. Baden-Baden: Nomos.

Mikulinskij, Semen R. et al. (1977a). Wissenschaftliche Schulen. Band 1. Berlin: Akademie-Verlag.

Mikulinskij, Semen R. et al. (1977b). Wissenschaftliche Schulen. Band 2. Berlin: Akademie-Verlag.

Moebius, Stephan. 2006. Die Zauberlehrlinge. Das: Soziologiegeschichte Collège de Sociologie (1937-1939). Konstanz: UVK.

Moebius, Stephan. (2015a). René König und die „Kölner Schule“. Eine soziologiegeschichtliche Annäherung. Wiesbaden: Springer VS.

Moebius, Stephan. (2015b). René Königs Züricher Vorlesungen (1938-1952). In Zyklos. Jahrbuch für Theorie und Geschichte der Soziologie. Band 1, Hrsg. Martin Endreß, Klaus Lichtblau und Stephan Moebius, 251-282. Wiesbaden: Springer VS.

Moebius, Stephan. 2016. René König (1906-1992): Der Weg über die Kunst zur (Kunst-)Soziologie. In Klassiker der Soziologie der Künste. Prominente und wegweisende Ansätze, Hrsg. Christian Steuerwald, 405-432. Wiesbaden: Springer VS.

Moebius, Stephan. (2017a). Schulen, Akteure und regionale Zentren in der frühen Geschichte der bundesrepublikanischen Soziologie. In Handbuch Geschichte der deutschsprachigen Soziologie, Teilband 1: Geschichte der Soziologie im deutschsprachigen Raum, Hrsg. Stephan Moebius und Andrea Ploder, 391-426. Wiesbaden: Springer VS.

Moebius, Stephan. (2017b). Die Geschichte der Soziologie im Spiegel der Kölner Zeitschrift für Soziologie und Sozialpsychologie (KZfSS). Kölner Zeitschrift für Soziologie und Sozialpsychologie, Sonderheft 69: Soziologiegeschichte im Spiegel der Kölner Zeitschrift für Soziologie und Sozialpsychologie, Hrsg. Daniela Grunow, Thomas Schwinn und Michael Wagner, 3-44. Wiesbaden: Springer VS

Moebius, Stephan, und Martin Griesbacher. (i. E.) Einleitung. In René König: Zürcher Vorlesungen. Band 1. Berlin: Suhrkamp.

Neidhardt, Friedhelm. 2006. René König: ,Gleichzeitig der Sache und der Praxis dienen“. Erinnerung zum 100. Gebrutstag am 5. Juli 2006. In Berliner Journal für Soziologie 1:133-136.

Opp Karl-Dieter. 2010. Ein nicht vorhersehbarer Lebenslauf?. In Soziologische Karrieren in autobiographischer Analyse, Hrsg. Monika Jungbauer-Gans und Christiane Gross, 75-94. Wiesbaden: VS Verlag für Sozialwissenschaften.

Peter, Lothar. 2001. Warum und wie betreibt man Soziologiegeschichte. In Jahrbuch für Soziologiegeschichte 1997/98, Hrsg. Carsten Klingemann, Michael Neumann, Karl-Siegbert Rehberg, Ilja Srubar und Erhard Stölting, 9-64. Opladen: Leske + Budrich.

Peter, Lothar. 2014. Marx an die Uni-Die „Marburger Schule“. Geschichte, Probleme, Akteure. Köln: PapyRossa.

Peter, Lothar. 2015. Warum und wie betreibt man Soziologiegeschichte? In Soziologiegeschichte. Wege und Ziele, Hrsg. Christian Dayé und Stephan Moebius, 112-146. Berlin: Suhrkamp.

Pinn, Irmgard, und Michael Nebelung. 1990. Kontinuität durch Verdrängung. In Jahrbuch für Soziologiegeschichte 1990, Hrsg. Heinz-Jürgen Dahme, Carsten Klingemann, Michael Neumann, Karl-Siegbert Rehberg und Ilja Srubar,177-218. Opladen: Leske + Budrich.

Ploder, Andrea. 2017. Geschichte Qualitativer und interpretativer Forschung in der deutschsprachigen Soziologie nach 1945. In Handbuch Geschichte der deutschsprachigen Soziologie, Teilband 1: Geschichte der Soziologie im deutschsprachigen Raum, Hrsg. Stephan Moebius und Andrea Ploder, 735-760. Wiesbaden: Springer VS.

Price, Derek J. Solla. 1974. Little science, big science. Von der Studierstube zur Großforschung. 1963. Frankfurt a. M.: Suhrkamp.

Reichardt, Sven, und Mark Zierenberg. 2009. Damals nach dem Krieg. Eine Geschichte Deutschlands 1945-1949. München: Goldmann.

Römer, Oliver. 2018. Heinz Maus in Leipzig. Eine Konstellation in der Entwicklungsgeschichte der deutschen Soziologie um 1933. In Zyklos 4. Jahrbuch für Theorie und Geschichte der Soziologie, Hrsg. Martin Endreß und Stephan Moebius, 183-216. Wiesbaden: Springer VS.

Rüschemeyer, Dieter. 1996. In hindsight—-through a glass darkly. In Wege zur Soziologie nach 1945. Biographische Notizen, Hrsg. Christian Fleck, 327-337. Opladen: Leske + Budrich.

Sack, Fritz. 2010. Wie wurde ich Soziologe? In Soziologische Karrieren in autobiographischer Analyse, Hrsg. Monika Jungbauer-Gans und Christiane Gross 21-51. Wiesbaden: VS Verlag für Sozialwissenschaften.

Sahner, Heinz. 1982. Theorie und Forschung. Zur paradigmatischen Struktur der westdeutschen Soziologie und zu ihrem Einfluß auf die Forschung. Opladen: Westdeutscher Verlag. 
Sahner, Heinz. 1992. Einige Anmerkungen zur „Kölner Schule“. In René König. Gesamtverzeichnis der Schriften. In der Spiegelung von Freunden, Schülern, Kollegen. Hrsg. Heine von Alemann und Gerhard Kunz, 254-257. Opladen: Westdeutscher Verlag.

Schad, Susanne Petra. 1972. Empirical social research in Weimar-Germany. Paris: Mouton.

Schelsky, Helmut. 1959. Ortsbestimmung der deutschen Soziologie. Düsseldorf: Diederichs.

Scheuch, Erwin. 1992. ..., daß Wissenschaft Spaß macht. René König zum 85. Geburtstag. In René König. Gesamtverzeichnis der Schriften. In der Spiegelung von Freunden, Schülern, Kollegen. Hrsg. Heine von Alemann und Gerhard Kunz, 258-260. Opladen: Westdeutscher Verlag.

Scheuch, Erwin K. 1996. Es mußte nicht Soziologie sein, aber es war besser so. In Wege zur Soziologie nach 1945. Biographische Notizen, Hrsg. Christian Fleck, 199-219. Opladen: Leske + Budrich.

Scheuch, Erwin K. 1998. Wissenschaft - Anwendung - Publizistik: Drei Leben als Sozialwissenschaftler. In Soziologie als Beruf. Erinnerungen westdeutscher Hochschulprofessoren der Nachkriegsgeneration. Sonderband 11 der Sozialen Welt, Hrsg. Martin Bolte und Friedhelm Neidhardt, 233-266. BadenBaden: Nomos.

Scheuch, Erwin K. 2001. Soziologie in Köln. In Gute Gesellschaft? Verhandlungen des 30. Kongresses der Deutschen Gesellschaft für Soziologie in Köln 2000. Teil A, Hrsg. Jutta Allmendinger, 113-168. Opladen: Leske + Budrich.

Scheuch, Ute. 2008. Erwin K. Scheuch - Eine Biographie. Band I. Es mußte nicht Soziologie sein, aber es war besser so, mit einem Nachwort von Peter Atteslander. Bad Schussenried: Hess Verlag.

Schmidt Gert. 1980. Zur Geschichte der Industriesoziologie in Deutschland. Soziale Welt 31:257-278.

Schütz, Alfred. 2002. Der Heimkehrer. In Der Fremde als sozialer Typus, Hrsg. Peter-Ulrich Merz-Benz und Gerhard Wagner, 93-110. Konstanz: UVK.

Stichweh, Rudolf. 1999. Zur Soziologie wissenschaftlicher Schulen. In Schulen in der deutschen Politikwissenschaft, Hrsg. Wilhelm Bleek und Hans J. Lietzmann, 19-32. Opladen: Leske + Budrich.

Szacki, Jerzy. 1981. „Schulen“ in der Soziologie. In Geschichte der Soziologie. Studien zur kognitiven, sozialen und historischen Identität einer Disziplin, Hrsg. Wolf Lepenies, Bd. 2: 16-30. Frankfurt a. M.: Suhrkamp.

Tent, James F. 1998. Academic proconsul. Havard sociologist Edward Y. Hartshorne and the reopneing of German universities, 1945-1946. His Personal Account. Trier: WVT.

Tiryakian, Edward A. 1981. Die Bedeutung von Schulen für die Entwicklung der Soziologie. In Geschichte der Soziologie. Studien zur kognitiven, sozialen und historischen Identität einer Disziplin, Hrsg. Wolf Lepenies, Bd. 2: 31-68. Frankfurt a. M.: Suhrkamp.

Vierkandt, Alfred. 1931. Handwörterbuch der Soziologie. Stuttgart: Enke.

Wehler, Hans-Ulrich. 2006. Eine lebhafte Kampfsituation. Ein Gespräch mit Manfred Hettling und Cornelius Torp. München: Beck.

Weischer, Christoph. 2004. Das Unternehmen „Empirische Sozialforschung“. Strukturen, Praktiken und Leitbilder der Sozialforschung in der BRD. München: Oldenbourg.

Weiß, Johannes. 1992. Gehört René König zur „Kölner Schule“? In René König. Gesamtverzeichnis der Schriften. In der Spiegelung von Freunden, Schülern, Kollegen, Hrsg. Heine von Alemann und Gerhard Kunz, 274-277. Opladen: Westdeutscher Verlag.

Wiese, Leopold von. 1957. Erinnerungen. Köln: Westdeutscher Verlag.

Wiese, Leopold von. 1959. Die Deutsche Gesellschaft für Soziologie. Persönliche Eindrücke in den ersten fünfzig Jahren (1909-1959). In 50 Jahre Deutsche Gesellschaft für Soziologie, Kölner Zeitschrift für Soziologie und Sozialpsychologie 1, Hrsg. René König, 11-20. Stuttgart: Enke.

Wiggershaus, Rolf. 1988. Die Frankfurter Schule. Geschichte - Theoretische Entwicklung - Politische Bedeutung. 6. Aufl. München: DTV.

Zahn, Ernest. 1992. Zwischen Zürich und Amsterdam: René König und mein eigener Weg. In René König. Gesamtverzeichnis der Schriften. In der Spiegelung von Freunden, Schülern, Kollegen. Hrsg. Heine von Alemann und Gerhard Kunz, 278-283. Opladen: Westdeutscher Verlag.

Ziegler, Rolf. 1992. Nachdenken über „K - Faktor 1“. In René König. Gesamtverzeichnis der Schriften. In der Spiegelung von Freunden, Schülern, Kollegen. Hrsg. Heine von Alemann und Gerhard Kunz, 284-287. Opladen: Westdeutscher Verlag.

Ziegler, Rolf. 1998. In memoriam René König. Für eine Soziologie in moralischer Absicht. In René König, Soziologe und Humanist. Texte aus vier Jahrzehnten, Hrsg. Michael Klein und Oliver König, 20-32. Opladen: Leske + Budrich.

Ziegler, Rolf. 2010. Chancen und Herausforderungen - ein autobiographischer Rückblick. In Soziologische Karrieren in autobiographischer Analyse, Hrsg. Monika Jungbauer-Gans und Christiane Gross, 53-74. Wiesbaden: VS Verlag für Soziologie. 
Zürcher, Markus. 1995. Unterbrochene Tradition. Die Anfänge der Soziologie in der Schweiz. Zürich: Chronos.

Stephan Moebius Dr. Prof. für Soziologische Theorie und Ideengeschichte an der Universität Graz, Wirkliches Mitglied der Österreichischen Akademie der Wissenschaften, seit 2019 Sprecher der neu gegründeten Sektion Soziologiegeschichte der Deutschen Gesellschaft für Soziologie (DGS) u.v.m. Letzte Veröffentlichungen: René König und die ,Kölner Schule‘. Eine soziologiegeschichtliche Annäherung. Wiesbaden 2015; Handbuch Kultursoziologie. Bd. 1 und 2. Wiesbaden 2019 (hrsg. mit K. Scherke und F. Nungesser); Handbuch Geschichte der deutschsprachigen Soziologie. Bd. 1-3. Wiesbaden 2018 (hrsg. mit N. Holzhauser, A. Ploder und O. Roemer); Soziologische Denkschulen in der Bundesrepublik Deutschland. Wiesbaden 2019 (hrsg. mit J. Fischer); René König: Zürcher Vorlesungen (1938-1952). Bd. 1-4. Berlin 2020 (hrsg. mit M. Griesbacher).

Martin Griesbacher MA, Assistent am Forschungsnetzwerk Human Factor in Digital Transformation an der Universität Graz. Seit 2015 Ko-Organisator der interdisziplinären Konferenz-Reihe Denkwerkstätte Graz. Forschungsschwerpunkte: Arbeitszeitforschung, Zeitsoziologie, Digitalisierung, Cybersecurity. Veröffentlichungen: Normalarbeit: Nur Vergangenheit oder auch Zukunft?, transcript 2018 (hrsg. mit J. Muckenhuber und J. Hödl); René König: Zürcher Vorlesungen (1938-1952). Bd. 1-4. Berlin 2020 (hrsg. mit S. Moebius). 